\title{
Historical Property Rights, Sociality, and the Emergence of Impersonal Exchange in Long-Distance Trade
}

\author{
By Erik O. Kimbrough, Vernon L. Smith, and Bart J. Wilson*
}

\begin{abstract}
This laboratory experiment explores the extent to which impersonal exchange emerges from personal exchange with opportunities for long-distance trade. We design a three-commodity production and exchange economy in which agents in three geographically separated villages must develop multilateral exchange networks to import a good only available abroad. For treatments, we induce two distinct institutional histories to investigate how past experience with property rights affects the evolution of specialization and exchange. We find that a history of unenforced property rights hinders our subjects' ability to develop the requisite personal social arrangements to support specialization and effectively exploit impersonal long-distance trade. (JEL C90, D23, D51, P14)
\end{abstract}

Specialization and exchange are at the core of economics, yet over 230 years after Adam Smith first presented his fundamental theorem, economists know remarkably little about how exchange evolves from personal social interactions-reinforced by local knowledge, reputations, and the prospect of future dealings - to impersonal market transactions undergirded by such formal institutions as impartial courts. Smith, however, merely posited the phenomena of specialization and exchange as an expression of a "propensity in human nature ... to truck, barter, and exchange one thing for another," effectively shifting the focus to wealth-creating specialization as a consequence of exchange. Ever since, save the important contributions of economic historians, the evolving process of exchange and specialization has been slighted. Laboratory experiments have mostly examined the efficiency properties of extant institutions or tested new institutions for field application; they have not inquired into the processes that account for the original emergence of market institutions.

The general argument from economic history is that informal norms are adequate for smallscale exchange within villages and hunter-gatherer societies, but that as nascent specialization and exchange grow, expanding across a larger area, these informal norms are off-loaded onto more formal, centralized rule systems. ${ }^{1}$ Such institutions develop to mitigate the increases in transaction costs resulting from greater possibilities for conflict (Douglass C. North 1990, 1991;

\footnotetext{
* Kimbrough: Interdisciplinary Center for Economic Science, George Mason University, 4400 University Drive, MSN 1B2, Fairfax, VA 22030-4444 (e-mail: ekimbrough@gmail.com); Smith: Economic Science Institute, Chapman University, One University Drive, Orange, CA 92866 (e-mail: vsmith@chapman.edu); Wilson: Economic Science Institute, Chapman University, One University Drive, Orange, CA 92866 (e-mail: bartwilson@gmail.com). We are grateful for the financial support of the International Foundation for Research in Experimental Economics, and thank Jeffrey Kirchner for his superb software programming. Reshma Hussam, Jason Liu, David Majors, David Phillips, Karl Schurter, and Zack Yang provided excellent research assistance, for which we thank them. Seminar participants at Colby College, University of Connecticut, Florida State University, George Mason University, and Miami University also provided valuable comments that have improved the paper.

${ }^{1}$ We should emphasize that some exchanges based on the reciprocity and sharing practices of local communities may tend to persist, and not be displaced, by formal centralized rule systems. Thus Robert C. Ellickson (1991) provides a case study of the persistence of local norms that ignore codified law in dealing with animal trespass.
} 
Avinash K. Dixit 2004). But what is this process of institutional evolution? What spawns transitions from the explicit reciprocity of personal exchange to the implicit cooperation of impersonal exchange? How and to what extent do institutions of the past constrain future trajectories of economic development?

Avner Greif $(1993,2006)$ reconstructs two specific lost histories of community-based systems of responsibility that supported impersonal exchange in medieval Europe and that laid the foundation for broader, law-based systems to eventually supplant them. Using the experimental method, this paper attempts to complementarily reconstruct our understanding of such transitions by directly observing how Smith's natural propensity expresses itself when cash-motivated participants discover and implement local and distal exchange networks in laboratory economies.

Some theorists have attempted to model the transition from personal to impersonal exchange. Rachel E. Kranton (1996) probes the relationship between personal and impersonal exchange in terms of the trade-offs between the two systems, highlighting relative transaction costs and product diversity. Her results hinge on the positive network effects derived from having more people using one form of exchange. Thus, she argues that, ceteris paribus, the initial composition of the population (in terms of which type of exchange each agent prefers) will drive the adoption of the exchange system preferred by the majority of agents, even when this decision is inefficient. When she introduces differences in the benefits derived from each type of exchange, she still concludes that for population distributions with "too many" agents involved in less efficient, personal exchange, a crowding out of market exchange can occur as a result of network effects. Kranton and Deborah F. Minehart (2001) also develop a model of the creation of buyer-seller networks in which agents pay an explicit cost in order to form "links" allowing them to engage in trade. Krishna B. Kumar and John G. Matsusaka (2006) propose a model of economic development that characterizes the efficacy of institutional arrangements in terms not only of the incentive properties of the institutions themselves, but also of the social capital that must be built up in the population in order to properly exploit them. They distinguish between two types of social capital, Village and Market, ${ }^{2}$ which differ in the types of institutions for which they are suited, and they conclude that the prevalence of village capital can hinder the growth of market institutions.

These models, while informative in their own rights, fail to capture the interesting aspects of our experimental design, as our subjects must live in both the personal and impersonal worlds simultaneously in order to succeed. In our paper, impersonal exchange is not a given that must be traded off against personal exchange; nor do our subjects make a binary choice to engage in either personal or impersonal exchange. Rather, we ask under what conditions will we observe impersonal, market exchange emerge out of personal, social exchange? And if we do observe this emergence, can we characterize what sorts of personal experiences our subjects draw upon in their problem-solving task? Since their life experiences include participation in both reciprocal social exchanges and market negotiations, our subjects must decide which attitude/behavior paradigm to apply to the experimental circumstances.

Furthermore, unlike historical investigations, in the laboratory we have the ability to induce different institutional histories in our economies and then observe how these different points of origin affect the developmental trajectories of the economies we study here. North argues that belief systems and the stock of local knowledge, the internal representations of the human experience, are intimately intertwined with the external institutions that humans build (North 2005). Therefore, we ask whether varying the degree to which property rights are historically enforced affects the ability of subjects to exploit opportunities for long-distance trade, even if property rights are exogenously enforced in the present.

\footnotetext{
${ }^{2}$ These correspond roughly to our use of personal and impersonal, respectively.
} 
To explore these questions, our experiment builds upon Sean Crockett, Vernon L. Smith, and Bart J. Wilson (2007), hereafter CSW, which examines the efficiency of a two-commodity production and exchange economy in which participants must first discover and develop a self-organized system of exchange before they can exploit the gains from specialization. In this paper we introduce opportunities for distal trade to emerge among three CSW economies. By introducing a third good and the ability for a subset of the participants to travel between villages, we provide ample opportunity for our subjects to set up more complex networks of exchange in order for us to gain insights into the transition from the personal to the impersonal.

CSW find that there are three interrelated stages in learning to achieve the competitive equilibrium in (replicator) economies of size two, four, and eight: (1) discovering the ability to exchange, which may require "mind-reading" (inferring intentions from words and actions) and imitation, (2) finding a suitably endowed partner with whom a subject can discover the benefits to exchange through specialization, and (3) building the relationship by increasing specialization over time. In these model economies, however, no market, as it is commonly conceived, ever emerges. People either do not exchange, or remain firmly entrenched in bilateral personal exchanges that are not characterized by the language typical of "bargaining" as we normally model it. Based on what CSW learned from these first treatments, they proceed to further explore (2) and (3) by gradually building the eight-person economies from smaller groups (hereafter the Build8 treatment). In particular, CSW begin each 40-period session with four two-person economies, merge these into two four-person economies after 20 periods, and finally merge these into one eight-person economy after 30 periods. The Build8 design significantly reduces the transaction/search costs of finding a suitable trading partner in the first 20 rounds, and allows gradual growth of the size of the economy. Merging two two-person economies introduces new potential trading partners who, having had the opportunity to discover their own comparative advantage, and being in the process of increasing their rate of specialization, could conceivably compete with the other participants in multilateral trading. Finally, if individuals have not yet discovered trade at the time of the merge, this allows them to imitate, or be explicitly taught the innovations discovered by others in exchange and specialization. CSW find that full specialization, and thus high efficiency, often occurs in the Build8 economies, but all exchange is bilateral and fundamentally personal.

This Build8 design serves as the experiential foundation for the two treatment conditions in this experiment; i.e., we first allow the subjects to explore two-, four- and eight-person communities in sequence in a two-commodity world, and then we introduce long-distance trade for a third commodity after this experience. Specifically, three-fourths of the subjects in an economy are drawn from two different treatment histories in Build8 sessions, one in which property rights in personal goods are perfectly enforced for all of the participants, though they must rely on trust and repeat interactions to enforce exchange agreements, and another in which no property rights of any kind are enforced. Hence, in both sets of history-inducing sessions, there is no external enforcement of exchange contracts and, as found by CSW, no need for such.

After these initial sessions, our subjects are placed in the three-good economy described below and we observe their relative performance. We find that historical experience with property rights increases the extent to which subjects are able to specialize and reap the gains from exchange. Furthermore, on the basis of our analysis of our subjects' chat-room transcripts, we find that interactions between those engaging in distal trade are of a much more impersonal character than are interactions between those who exchange locally. 


\section{The Environment and Institution}

\section{A. The Experimental World}

Our experimental world consists of three geographically separated villages with a common meeting area between them. Three goods in total can be produced in the world: red, blue, and pink. Each village is capable of producing only two of the three such that there is a red-blue village, a blue-pink village, and a pink-red village. Persons 1 through 4 reside in the red-blue village, 5 through 8 in the blue-pink village, and 9 through 12 in the pink-red village.

Within each village, the four people are divided into two types, "producers" and "merchants," a distinction in terms we use solely for describing the environment to the reader here. ${ }^{3}$ We identify agents by their respective roles and on-screen identification numbers as follows: producerl, producer 2, merchant 3 , and merchant 4 are in the red-blue village; producer 5 , producer 6 , merchant 7 , and merchant 8 are in the blue-pink village, and so on. Producers are capable of producing twice as much of each good as merchants, but merchants have the additional ability to travel to the merchant meeting area which remains unseen to the producers. There they can discover that mutually beneficial trade is possible with merchants from the other two villages. These two types are further divided into odds and evens. To prevent this description from becoming too unwieldy, we will discuss the details in the context of the red-blue village and then extrapolate to the other villages, which are each symmetric to the red-blue village.

\section{B. Preferences and Production}

Without the third good, pink, each subject in the red-blue village prefers to consume red and blue in the strict complementary proportions of CSW. In addition, if the merchants are able to acquire pink, the consumption of each unit acts as a multiplier on that individual's earnings from consuming red and blue. In the red-blue village, which we will denote with the superscript ${ }^{r, b}$, the utility over $r$ units of red, $b$ units of blue, and $p$ units of pink for an even and an odd are

$$
\begin{gathered}
U_{\text {odd }}^{r, b}=\left\{\begin{array}{lr}
\min \{r, 3 b\}, & p<2 \\
7 / 8 \ln (p+2) \cdot \min \{r, 3 b\}, & 2 \leq p<26 \\
2.91 \cdot \min \{r, 3 b\}, & p \geq 26
\end{array}\right. \\
U_{\text {even }}^{r, b}=\left\{\begin{array}{lr}
\min \{2 r, b\}, & p<2 \\
7 / 8 \ln (p+2) \cdot \min \{2 r, b\}, & 2 \leq p<26 \\
2.91 \cdot \min \{2 r, b\}, & p \geq 26
\end{array}\right.
\end{gathered}
$$

We chose this functional form for the third good for three reasons. First, it adjusts the preferences such that, while consumption of the third good is not necessary in order create earnings, it has a nontrivial impact on welfare for every agent, thereby providing a relatively powerful individual incentive to acquire the third good. Second, we chose a logarithmic function to incorporate decreasing returns to the consumption of the third good. And, finally, the coefficient of $7 / 8$ scales the maximum earnings in the village economy to more than double the maximum possible earnings of each individual with long-distance trade.

\footnotetext{
${ }^{3}$ As the instructions indicate, individuals in the experiment are referred to only abstractly as "Person $j$." The subjects must discover the opportunities available to them as "producers" or as "merchants."
} 
The agents in the other villages have the same corresponding preferences; odds always need a 3-to-1 ratio of the first good in their village's name to the second, and evens always need a 2-to-1 ratio of the second good to the first. The separable functional form of the third good is the same across all villages. For example, merchant7 in the blue-pink village has the following preferences:

$$
U_{\text {odd }}^{b, p}=\left\{\begin{array}{lr}
\min \{b, 3 p\}, & r<2 \\
7 / 8 \ln (r+2) \cdot \min \{b, 3 p\}, & 2 \leq r<26 \\
2.91 \cdot \min \{b, 3 p\}, & r \geq 26
\end{array}\right.
$$

Odds and evens also differ in their production functions. Each agent in the red-blue village is endowed a fixed amount of $T=10$ seconds to divide between producing $R$ units of red and $B$ units of blue. Let $t$ denote time in seconds for producing $R$. Odd producers generate output according to the following functions:

$$
\begin{gathered}
R_{\text {odd }}^{r, b}=\frac{13}{10 \sqrt{10}} t^{5 / 2} \approx 0.41 t^{5 / 2}, \\
B_{\text {odd }}^{r, b}=\frac{10}{10-\left(\frac{300 \sqrt{10}}{13}\right)^{2 / 5}}(10-t) \approx 2.25(10-t) .
\end{gathered}
$$

For the even producers, the production functions are

$$
\begin{gathered}
R_{\text {even }}^{r, b}=\frac{13}{10-\sqrt{\frac{260}{11}}} t \approx 2.53 t, \\
B_{\text {even }}^{r, b}=\frac{11}{10}(10-t)^{2} .
\end{gathered}
$$

This gives odd producers a comparative (and absolute) advantage in red and allows them to produce a maximum of 130 red at $t=10$ or just 23 blue at $t=0$, and it allows evens to produce a maximum of 25 red or 110 blue. Members of the other villages are correspondingly endowed according to the name of their village. For example, producer 9 in the pink-red village produces according to the following function:

$$
\begin{gathered}
P_{o d d}^{p, r}=\frac{13}{10 \sqrt{10}} t^{5 / 2} \approx 0.41 t^{5 / 2}, \\
R_{\text {odd }}^{p, r}=\frac{10}{10-\left(\frac{300 \sqrt{10}}{13}\right)^{2 / 5}}(10-t) \approx 2.25(10-t),
\end{gathered}
$$

where $P$ is the number of pink units produced. (Compare with producerl's $R_{o d d}^{r, b}$ and $B_{o d d}^{r, b}$ above.) 
As mentioned above, producers and merchants also have differences in their production functions. Merchants can produce exactly one-half as much of each good as producers, e.g., $R_{\text {odd, merchant }}^{r, b}=1 / 2 R_{\text {odd }}^{r, b}$.

\section{Analytical Benchmarks}

In autarky, odd (even) producers maximize their earnings by spending 56 percent (51 percent) of their $T=10$ seconds producing red, thus producing and consuming 30 (13) red and 10 (26) blue and earning 30 (26) cents each period. Spending the same amount of time producing each good, odd (even) merchants earn a total of 15 (12) cents. ${ }^{4}$

A pair of producers within a village can roughly triple their earnings by specializing and trading only with each other. The odd producers specialize completely in the production of the red good, producing 130 units, while the even producers specialize in the blue good, producing 110 units. The competitive price of a blue unit is $4 / 3$ of a red unit, and after exchanging at this price, the odd producer consumes 90 red and 30 blue, while the even producer consumes 40 red and 80 blue. For a pair of merchants, the earnings at the competitive equilibrium are exactly one-half the amount earned by producers.

Finally, with intervillage trade, both producers and merchants maximize their potential earnings by remaining fully specialized in their production in each village, but they use a portion of that production to purchase the third good (via merchant intermediaries) from other producers and merchants in the other villages. Since, by design, the ratio of each good to every other good in the world is exactly 1 to 1 (world gross production is 360 each of red, blue, and pink when fully specialized), the competitive price of each good in terms of each other good in the intervillage arena is 1 . Let's assume that odd (even) producers trade with their counterpart producer within their own village. Given the decreasing marginal utility to pink, the optimal producer consumption of red and blue would be 72 (32) reds and 24 (64) blues. They could then transfer the remaining 26 reds ( 22 blues) to a merchant to exchange for an equal number of pinks from the other villages. If the producers consumed all of those pinks themselves, their maximum earnings would be 208 (178) cents. The earnings of a pair of merchants will not be exactly half of the earnings of the producers because of the decreasing marginal utility of the third good. Rather, the odd (even) merchant earns 85 (72) cents by consuming 36 (16) reds and 12 (32) blues and trading the remaining goods (13 reds and 11 blues) for an equal number of pinks from the other villages. The other villages mirror this with their own respective goods. Assuming the agents pair off in this fashion, the total earnings with intervillage trade are 543 cents per day in each village.

This benchmark with intervillage trade overlooks one important aspect of the geography, namely, that the producers can acquire the third good only through the merchants within their village, and it assumes that these merchants do not extract a margin from providing such a service. With two merchants in each village, one could posit that Bertrand competition would reduce the margin of the middlemen to zero. The impact of this intravillage tension between the production-blessed producers and the geographically blessed merchants is exactly what we wish to observe. To what extent does this tension promote more impersonal and multilateral exchange within the village?

\footnotetext{
${ }^{4}$ Based on the production functions described, it would seem that even merchants should earn 13 cents, but because their consumption preferences require that they consume a 2-to-1 ratio, one blue is wasted each turn.
} 


\section{Institution}

At this point in experimental papers that study markets, a section would normally describe the operant institutions - message space and rules governing message exchange and how messages become allocations. In the experiment reported here, any institutions of trade must be discovered and developed by the subjects, unaided by instructional guidance. One of the key objectives of the study is to observe the institutions that emerge in the environment that we place the subjects in. We do, however, provide the subjects with a message space: written English language (minimally constrained), and a "chat room" where all subject generated messages in a village are displayed. A similar message space is provided where the merchants meet. These will be described in the next section, and discussed extensively in what follows.

\section{Experimental Design and Procedures}

\section{A. Village and Meeting Area Interface}

An example of the subject interface for the red-blue village is displayed in Figure 1. Each subject owns both a house and a field. The house displays what will be consumed at the end of a period and the field displays what is produced during the production period. One-half of the subjects in each village, the merchants, also own a bucket. The bucket displays goods that the merchant carries with him to the common meeting area. The total quantity of each good contained within the house, field, or bucket is displayed on the icon itself at all times. The subjects can click on their field, house, or bucket to view the moveable contents of each in the upper-left section of the screen.

As we describe below, all subjects have prior experience with a CSW or related economy, so in contrast to CSW, we inform our subjects in the instructions that they can move goods with the single sentence: "You can move items to other people, and they can move items to you." At any time during the experiment, subjects may communicate with the other people in their village in a central chat room. They can discuss whatever they want so long as they do not use inappropriate language, discuss side payments, or make threats. Also, there is a space beneath each house where the owner may leave a one-line message that is always visible to other villagers.

In addition to the aforementioned abilities, merchants can click on a button labeled "travel" on the right side of their screen at any time to move to the common meeting area (shown in Figure 2) with two more chat rooms. When they travel, their buckets, and anything contained in those buckets, travel with them. On this screen, individuals interact with merchants from the other villages, and this is where intervillage trade, if it is to happen, must take place. Any goods acquired in the meeting area must be taken back to the villages and placed in a house to be consumed. In the meeting area or village, anything left in a bucket at the end of a day is wasted.

\section{B. The Experimental "Day"}

An experimental session is comprised of 40 "days" with each day divided into two phases, A and B. ${ }^{5}$ Phase $\mathrm{A}$ is the 10 -second production period during which each subject produces goods in his field using a scroll-wheel (see the top of Figure 1). This scroll-wheel can be adjusted at any time during the experiment to allocate production time for the next day. As production occurs, icons representing each of the goods appear in the subject's field.

\footnotetext{
${ }^{5}$ Some of our sessions ran more slowly than others, but every session lasted at least 34 days. As a result, we use days 29-34 for across-session comparisons.
} 


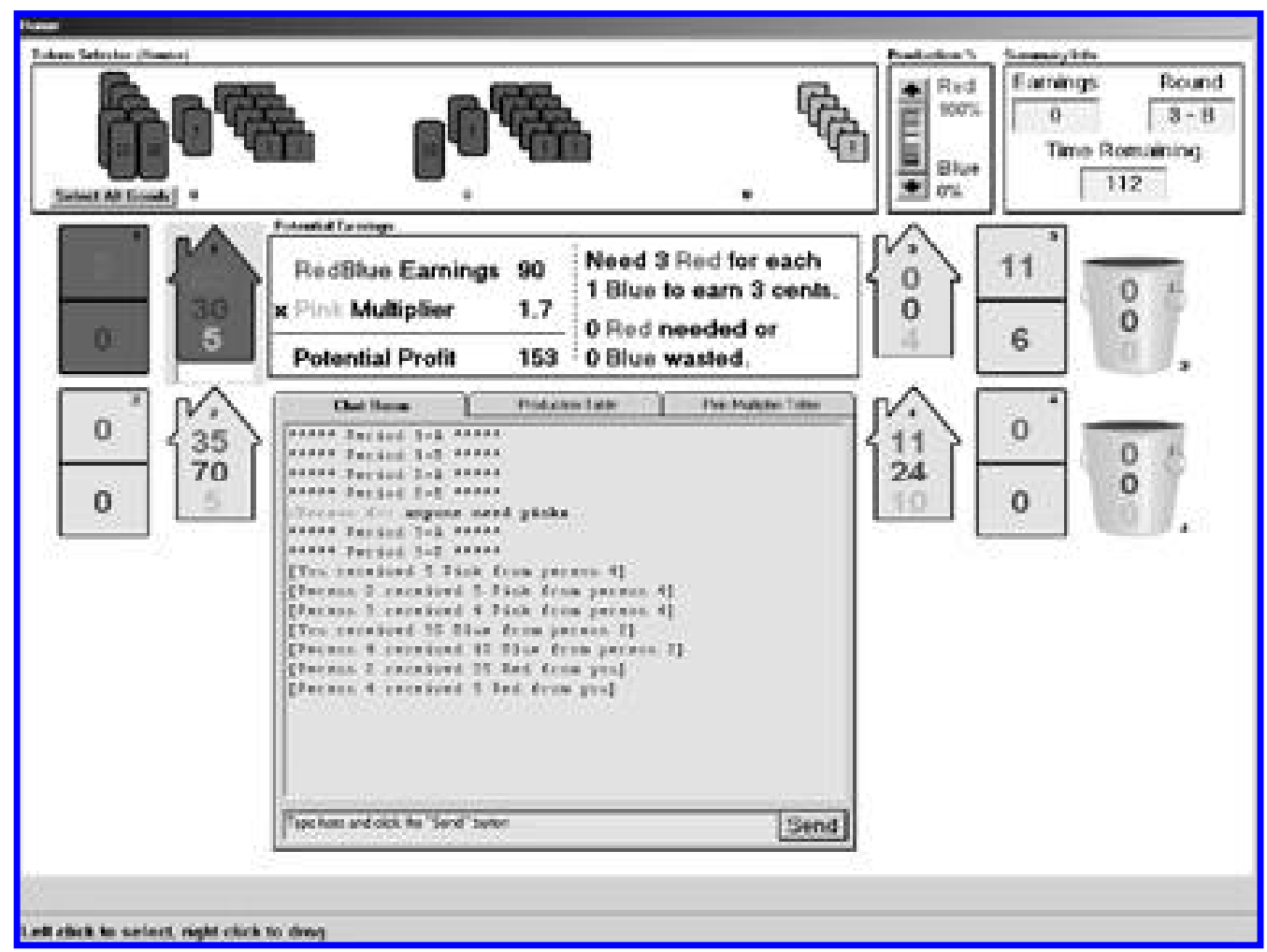

Figure 1. Red-Blue Village Interface

The day continues in Phase B for another 120 seconds in which these icons for goods can be dragged and dropped into any of the houses, fields, or buckets on the screen. A subject's own house and field are green, while those of others are gray. To earn cash, the subjects consume by dragging and dropping the red, blue, and pink icons into their houses. Anything not in a house at the end of a day and any goods not consumed in the proportions specified above perish at the end of the day. Every seventh day is a 130-second rest period, during which no production or consumption takes place, but during which subjects may still use the chat rooms at their leisure.

\section{Treatments}

An early test of the software revealed that our subjects would benefit from prior experience with this environment to more comprehensively absorb its complexity. Thus, we designed our experiment as a two-day session from which we then derived our two treatment conditions. On the first day, eight of the twelve subjects participated in a Build8 treatment as in CSW. Then, on the second day, they returned to participate in the experiment described above and were joined by four subjects who had participated in any one of the CSW treatments. No subject participated in this experiment twice.

We used the first day of the experiment to introduce two distinct histories to groups of eight of the participants, and then on the second day we put all twelve subjects in the experiment described above. We wish to observe the impact of this single difference in histories on the evo- 


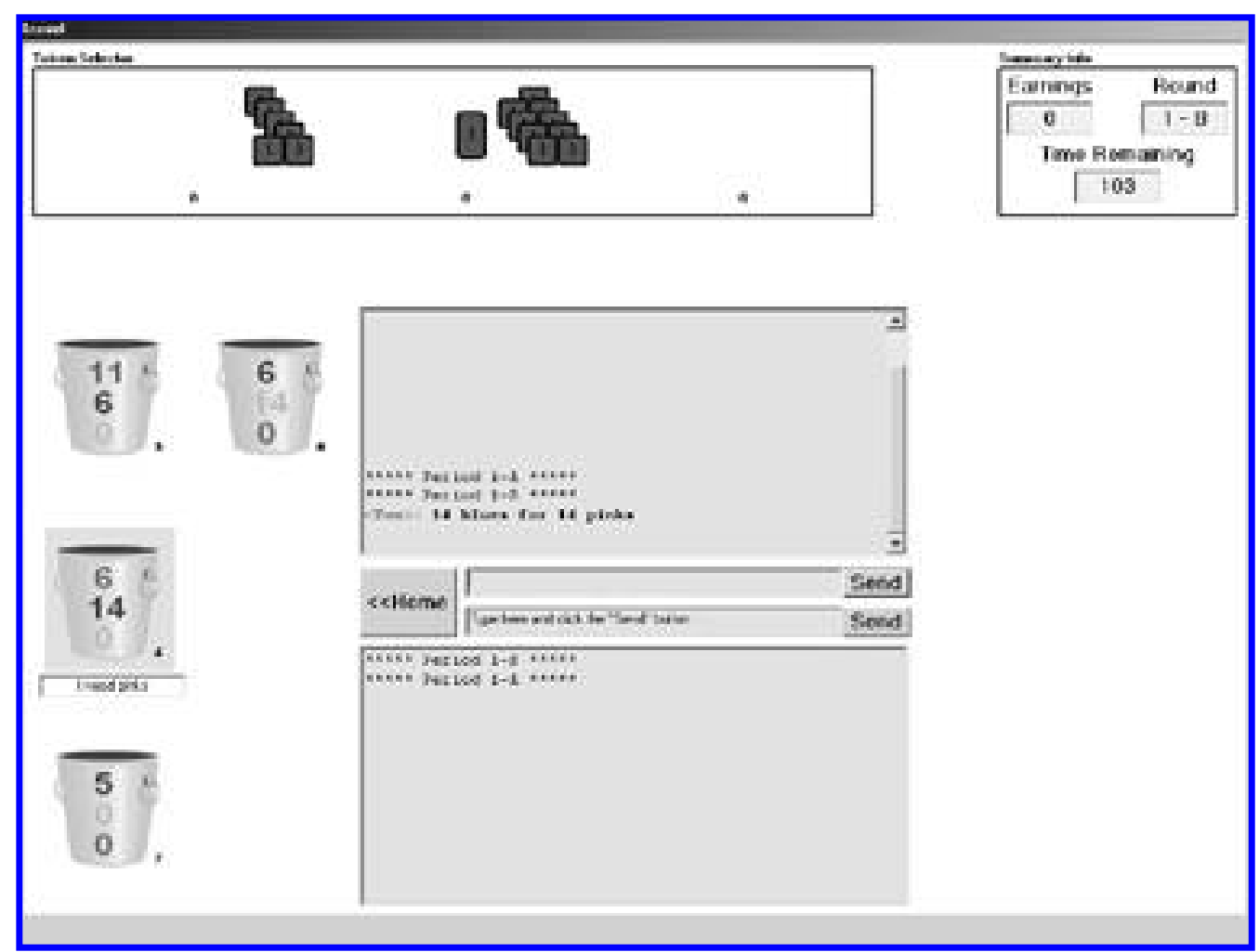

Figure 2. Meeting Area Interface

lution of specialization and long-distance exchange. Specifically, we ran a total of eight sessions, four with the same Build 8 design described above and four with a modest modification to the software for the Build8 design. The second design, to which we will attach the suffix "NPR" to Build8, is identical in every way to the Build 8 design except that absolutely no property rights are enforced. Any individual is able to move items into and out of any other individual's home and field. We give the subjects in Build8-NPR no additional information, i.e., they must discover the ability to steal in the same way that they must discover the ability to exchange in Build8. For the sake of parsimony, we will refer to the four Build8 (history) sessions in this paper as Build8-PR. Our hypothesis is that we will observe lower levels of both efficiency and specialization in the Build8-NPR treatment vis-à-vis the Build8-PR treatment.

Thus, these two history-inducing treatments form the basis for our two treatment conditions examining the evolution of personal exchange and the potential for impersonal exchange to emerge with opportunities for long-distance trade. We denote the "Property Rights History" treatment by $P R H$ and the "No Property Rights History" treatment as NPRH, and each session within a treatment is identified by a numerical suffix attached to the treatment name. For example, NPRH3 is the third session in the "No Property Rights History" treatment. Recall that the "history" portion of the treatment name refers to the participants' prior experiences with or without enforceable property rights in a CSW-type environment, but that all these sessions are conducted with the exact same procedures on the second day. That is, both introduce identical possibilities for long-distance trade with the same enforceable property rights. 


\section{Procedures}

Each of the eight sessions is comprised of twelve George Mason University undergraduates, recruited from the aggregate student body. Eight of the subjects in each session participated the previous day in our two versions of the Build8 treatment studied in CSW, while the remaining four were recruited from the list of those who had previously participated in any one of the treatments in CSW. ${ }^{6}$ The subjects interacted via visually isolated computer terminals and were randomly assigned a seat. One of the authors read a set of instructions aloud while the participants followed along on the screen prior to the beginning of the first period.

Subjects who participated in both sessions (for example, in the Build8- $P R$ and $P R H$ treatments) received a total of $\$ 15.00$ for showing up on time for both sessions, plus what they earned in the sessions. The subjects who participated only in the second session (for example, just the $P R H$ treatment) received $\$ 5.00$ for showing up on time. In addition to the show-up payment, we privately paid the participants all of their earnings and show-up payments at the conclusion of the second session. The average total earnings across the eight sessions are $\$ 17.20$, ranging from $\$ 2.58$ to $\$ 42.60$, to which the show-up payments are added. The first session lasted on average 90 minutes and the second 105 minutes.

\section{Hypotheses}

To reiterate, our objective with this experiment is to illuminate the process of transition from personal to impersonal exchange. Following Greif and North, we argue that past institutional and social histories may constrain the developmental possibilities of future social arrangements in a given environment. Thus, our subjects' history-conditioned expectations regarding the environment and each other's behavior will differ across treatments, and this difference will elicit noticeable differences in the observable outcomes of these economies. We hypothesize that economies whose villagers share a common experience with property rights will produce at higher levels of specialization and have concomitant higher earnings.

We conjecture that the CSW economies failed to produce impersonal, market-like exchange for two reasons: (1) the geography provided no context for in- and out-group constructions, and (2) solving the production and consumption problem did not require multilateral exchange. ${ }^{7}$ In this experiment, the introduction of merchants and the third good creates conditions such that, in order to maximize earnings, subjects must expand beyond simple bilateral exchanges into more complex, multilateral networks of exchange. Thus, merchants bearing red and blue must trade with up to four merchants from other villages to obtain sufficient pink for four hometown villagers. And in developing these networks, subjects must interact with others from different geographical locations. We hypothesize that geographical separation and the necessity of multilateral ties for success will educe impersonal exchange in the common meeting area.

Furthermore, with straightforward economic reasoning, we hypothesize that impersonal exchange will manifest itself within a village due to competition for and between merchants. We

\footnotetext{
${ }^{6}$ The sole exception is the fourth $N P R H$ session. Only six subjects showed up for the first day of the experiment (it was a Build6 rather than a Build8), and the six remaining subjects were recruited from those who had been in a CSW session. We note (see Figure 4) that having six rather than eight from the history-inducing session did not help the performance of NPRH4.

${ }^{7}$ Initially, CSW thought that their subjects might find it natural to use multilateral exchange, though it was not necessary for fully efficient wealth creation. After learning from the experiment that subjects instinctively "pair off," they used their Build 8 treatment to enable subjects to adapt bilateralism to progressively larger $(2,4$, and 8$)$ villages. This suggests an alternative sequential design structure: begin with three-person, two-commodity villages that require multilateralism for efficiency, and proceed based on how the subjects adapt to that economic environment. Does this history better prepare people for efficient adjustment to long-distance trade than we observe here?
} 
also conjecture that the merchants will take a margin of product as a fee for the valuable service they render, though competition for producers may make that margin quite small.

\section{Results}

\section{A. Our History-Inducing Sessions}

We begin by comparing the degree of specialization and efficiency of our four Build8-NPR sessions with our four Build8-PR sessions (plus the six Build8 sessions in CSW). ${ }^{8}$ The four panels in Figure 3 summarize the results from these eight history-inducing sessions. For convenience in discussing results, we will refer to days 1-6 as "week 1," days 8-13 as "week 2," etc. ${ }^{9} \mathrm{We}$ define efficiency in day $d$ as ((Total Realized Profit - Autarky Profit)/(Competitive Equilibrium Profit - Autarky Profit) $\times 100$ percent $)$, the average efficiency for the week as the average daily efficiency, and the degree of specialization as the total number of units produced divided by the maximum number of units produced when all agents are fully specialized. Finding 1 compares the specialization and efficiency of the Build8-NPR and Build8-PR treatments.

FINDING 1A: The Build8-NPR sessions are marginally less specialized than the Build8-PR sessions.

\section{EVIDENCE:}

The mean realized level of specialization in week 6 is 74.1 percent in the Build8- $P R$ sessions and 56.4 percent in the Build8-NPR sessions, which are marginally statistically different from each other $\left(U_{10,4}=31, p\right.$-value $=0.0709$, one-sided test $)$.

FINDING 1B: The Build8-NPR sessions are as efficient as the Build8-PR sessions.

\section{EVIDENCE:}

In week 6 the overall mean efficiency in the four Build8-PR sessions is 43.8 percent, while in the Build8-NPR session the mean efficiency is only 17.4 percent. Because the variation is much larger in Build8-NPR than Build8-PR, there is no significant difference in the mean efficiency $\left(U_{10,4}=28, p\right.$-value $=0.1518$, one-sided test $)$.

Even if the sessions are similarly specialized, the rate at which they efficiently consume the production may not be the same due to rampant theft in the Build8-NPR treatment. However, that is not the case. When taken in aggregate, there are small differences in the two basic metrics of these history-inducing treatments: efficiency and degree of specialization. As Figure 3 illustrates, the variance of the Build 8 -NPR treatment is quite high. Surprisingly, the most efficient and most highly specialized session is the third Build8-NPR session, at 74.2 percent efficiency and 88.8 percent specialization. Despite the lack of any enforceable property rights, it is remarkable that the villagers voluntarily respect each other's property, as this is clearly not the case in Build8NPR1 and Build8-NPR2. These two sessions strongly confirm our hypothesis. Both begin much the same as the other sessions described in CSW, steadily increasing their efficiency and specialization over time, but eventually stealing crowds out specialization and cooperative exchange during the final weeks when all of the participants merge into one eight-person economy. The

\footnotetext{
${ }^{8}$ Since our Build8-PR sessions and CSW's Build 8 sessions are conducted under the same conditions, we augmented the sample size to provide a pool of trained subjects for the new design and experiment reported here.

${ }^{9}$ Recall that every seventh day involves no production or consumption.
} 

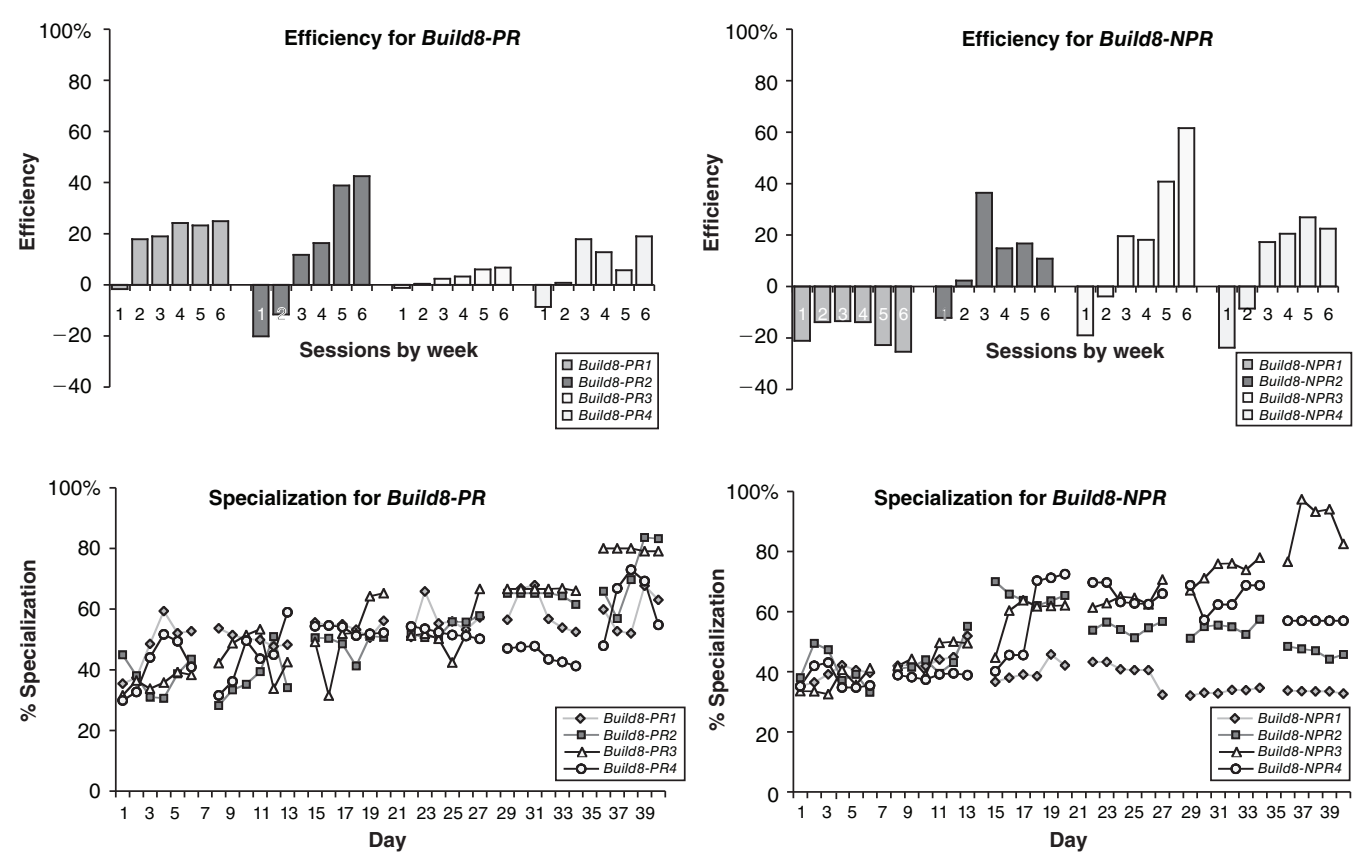

Figure 3. Efficiency and Specialization Rates of History-Inducing Sessions

first session, Build8-NPR1, actually performs worse in its final week than in its first week and is 25 percent less efficient than autarky. The Build8-NPR4 also degenerates slightly over time, but to a lesser degree.

\section{B. Historical Property Rights and the Evolution of Exchange}

Though the results from the history-inducing experiments in the new sessions (first day) are indistinct, the social underpinnings of these different histories have a striking impact on the subsequent trajectories of our eight multivillage economies (see the clear distinction in Figure 4). The height of each column in this figure displays the average daily earnings in each economy in week 5. All four $P R H$ economies have higher week 5 earnings than any of the four economies in the $N P R H$ treatment. Furthermore, all four $N P R H$ economies fail to reach the competitive equilibrium earnings of a village without intervillage trade, whereas three of the $P R H$ economies clearly exceed this benchmark. These results illustrate the path dependence of the end states achieved, as we report in our next finding:

FINDING 2: PRH economies are markedly wealthier than NPRH economies.

\section{EVIDENCE:}

Table 1 reports the sum of week 5 (and 6 where available) earnings by village and economy. The average total earnings per economy for $P R H$ are 5,746 cents in week 5, whereas average $N P R H$ earnings are 31.8 percent lower, or 3,916.25 cents. This difference is highly significant $\left(U_{4,4}=16, p\right.$-value $=0.0143$, one-sided test $)$.

Not only are the $P R H$ economies wealthier, the distribution of earnings in $P R H$ economies is noticeably more equitable between merchants and producers within each economy. Figure 4 also 
Table 1-Earnings in Cents and Specialization Rates by Village and Session

\begin{tabular}{|c|c|c|c|c|c|c|c|c|c|}
\hline $\begin{array}{l}\text { Session/ } \\
\text { village }\end{array}$ & $\begin{array}{l}\text { Earnings } \\
\text { week } 5\end{array}$ & $\begin{array}{l}\text { Earnings } \\
\text { week } 6\end{array}$ & $\begin{array}{l}\text { Specialization } \\
\text { week } 5\end{array}$ & $\begin{array}{l}\text { Specialization } \\
\text { week } 6\end{array}$ & $\begin{array}{l}\text { Session/ } \\
\text { village }\end{array}$ & $\begin{array}{l}\text { Earnings } \\
\text { week } 5\end{array}$ & $\begin{array}{l}\text { Earnings } \\
\text { week } 6\end{array}$ & $\begin{array}{l}\text { Specialization } \\
\text { week } 5\end{array}$ & $\begin{array}{l}\text { Specialization } \\
\text { week } 6\end{array}$ \\
\hline PRHI & & & & & NPRHI & & & & \\
\hline Red-Blue & 1,356 & 1,046 & 74.6 & 78.2 & Red-Blue & 780 & N/A & 38.0 & N/A \\
\hline Blue-Pink & 2,579 & 2,183 & 94.5 & 93.9 & Blue-Pink & 2,357 & N/A & 89.2 & N/A \\
\hline Pink-Red & 1,516 & 1,427 & 95.7 & 99.8 & Pink-Red & 1,220 & N/A & 93.6 & N/A \\
\hline Average & 1,817 & 1,552 & 88.3 & 90.6 & Average & $1,452.3$ & N/A & 73.6 & N/A \\
\hline Sum & 5,451 & 4,656 & & & Sum & 4,357 & & & \\
\hline PRH2 & & & & & NPRH2 & & & & \\
\hline Red-Blue & 2,288 & N/A & 100.0 & N/A & Red-Blue & 1,169 & N/A & 87.5 & N/A \\
\hline Blue-Pink & 1,964 & N/A & 100.0 & N/A & Blue-Pink & 1,826 & N/A & 100.0 & N/A \\
\hline Pink-Red & 1,992 & N/A & 98.3 & N/A & Pink-Red & 738 & N/A & 32.3 & N/A \\
\hline Average & $2,081.3$ & N/A & 99.4 & N/A & Average & $1,244.3$ & N/A & 73.3 & N/A \\
\hline Sum & 6,244 & & & & Sum & 3,733 & & & \\
\hline PRH3 & & & & & NPRH3 & & & & \\
\hline Red-Blue & 1,725 & 1,391 & 93.1 & 93.1 & Red-Blue & 2,277 & 2,137 & 100.0 & 98.7 \\
\hline Blue-Pink & 3,084 & 2,570 & 100.0 & 100.0 & Blue-Pink & 541 & 542 & 33.1 & 32.5 \\
\hline Pink-Red & 1,915 & 1,664 & 78.6 & 81.8 & Pink-Red & 1,636 & 1,435 & 80.5 & 79.9 \\
\hline Average & $2,241.3$ & 1,875 & 90.6 & 91.6 & Average & $1,484.7$ & $1,371.3$ & 71.2 & 70.4 \\
\hline Sum & 6,724 & 5,625 & & & Sum & 4,454 & 4,114 & & \\
\hline PRH4 & & & & & NPRH4 & & & & \\
\hline Red-Blue & 1,747 & 1,385 & 100.0 & 100.0 & Red-Blue & 1,121 & 1,208 & 72.8 & 74.2 \\
\hline Blue-Pink & 1,292 & 1,214 & 97.3 & 97.3 & Blue-Pink & 948 & 832 & 43.3 & 44.4 \\
\hline Pink-Red & 1,526 & 1,392 & 100.0 & 100.0 & Pink-Red & 1,052 & 1,025 & 61.1 & 61.1 \\
\hline Average & $1,521.7$ & $1,330.3$ & 99.1 & 99.1 & Average & $1,040.3$ & $1,021.7$ & 59.1 & 59.9 \\
\hline Sum & 4,565 & 3,991 & & & Sum & 3,121 & 3,065 & & \\
\hline $\begin{array}{l}\text { PRH Average } \\
\text { Sum }\end{array}$ & 5,746 & & & & $\begin{array}{l}\text { NPRH } \\
\text { Average } \\
\text { Sum }\end{array}$ & $3,916.3$ & & & \\
\hline PRH Average & $1,915.3$ & & 94.3 & & $\begin{array}{l}\text { NPRH } \\
\text { Average }\end{array}$ & $1,305.4$ & & 69.3 & \\
\hline
\end{tabular}

displays the earnings of the producers and merchants within each village. Despite a 50 percent handicap in production, $P R H$ merchants earn on average 70 percent of their corresponding producers in week 5. In the first three $N P R H$ economies, the average ratio of merchant-to-producer earnings in Figure 4 is only 45 percent. Merchants and producers have quite equitable earnings in NPRH4. On average, merchants earn almost exactly as much as the producers in this session, but this is also the poorest and most inefficient economy of the eight. It is possible that the low relative earnings of the merchants in the $N P R H$ treatment follow from a failure to engage in intervillage trade, but for week 5 , the average daily number of goods traded between villages was 63.5 in the $P R H$ economies and 65.3 in NPRH economies. ${ }^{10}$ We will return to this in the next subsection.

Our third finding is that the key reason why NPRH economies are so much poorer than their $P R H$ counterparts is that they are much less specialized:

\footnotetext{
${ }^{10}$ The average for the NPRH treatment omits the gifts of one merchant's entire production to another. This merchant, after being a rampant thief on the previous day, proclaimed himself to be a "Jesus type" on the second day and earned less than $\$ 3$ over the course of the 40 days.
} 


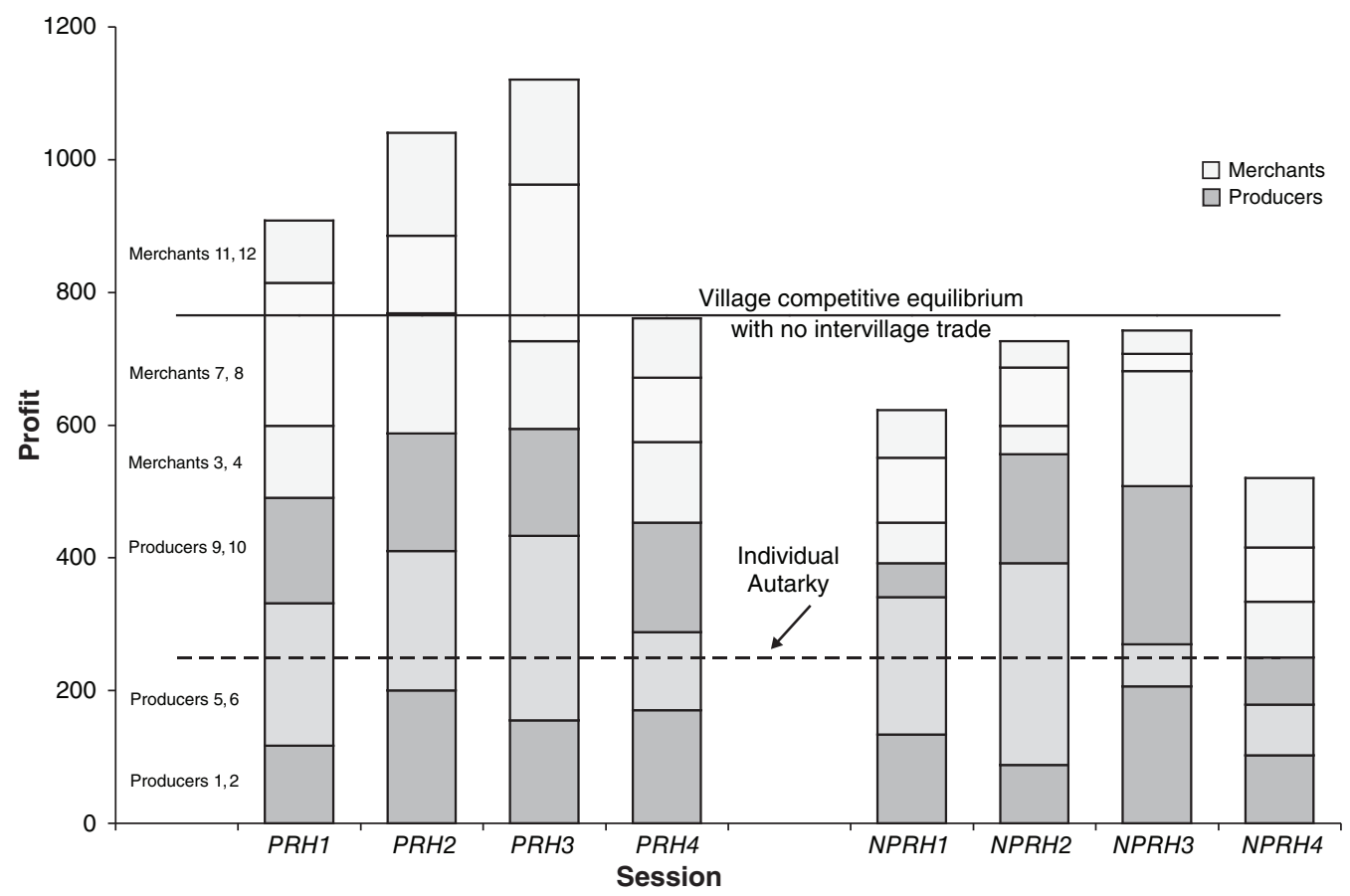

Figure 4. Average Daily Earnings by Session over Week 5 (cents)

FINDING 3: PRH economies are strikingly more specialized than NPRH economies.

\section{EVIDENCE:}

Table 1 reports that in week 5 the average rate of specialization by villages is 94.3 percent in the $P R H$ treatment and only 69.3 percent in the NPRH treatment. This difference is highly significant $\left(U_{4,4}=16, p\right.$-value $=0.0143$, one-sided test $)$.

This finding is all the more striking considering that there is no statistical difference in the rates of specialization in the history-inducing sessions (Finding 1A). But there is an economic difference in subject experience in the two differently induced histories and this carries over into the economies with long-distance trade. Scanning the second column from the right in Table 1, we notice that there is always one village in each NPRH economy that is less than 44 percent specialized, while the fourth column reports that the lowest rate of specialization in the entire $P R H$ treatment is 75 percent. The transcripts reveal the source of this difference: sociality, which we will discuss further in the next subsection. Figures 5 and 6 plot the efficiency of the two sessions by village. Every $N P R H$ economy has at least one village that holds the entire economy back by failing to specialize. In the case of $N P R H 3$, it is the blue-pink village. In contrast, the villages in the PRH economies either all move together, as in the PRH2 and PRH4, or there is a single village that is on a high growth path that leads the entire economy towards higher wealth. Figure 6 illustrates this for the PRH3 economy.

We now turn our attention to the personal and impersonal tone of the discussions interwoven into the item exchanges within and between villages. Erik Kimbrough, Smith, and Wilson (2008), hereafter KSW, reports a single pilot session of this experiment in which the tenor of the transcripts changes sharply when one moves from the village to the merchant meeting area. 


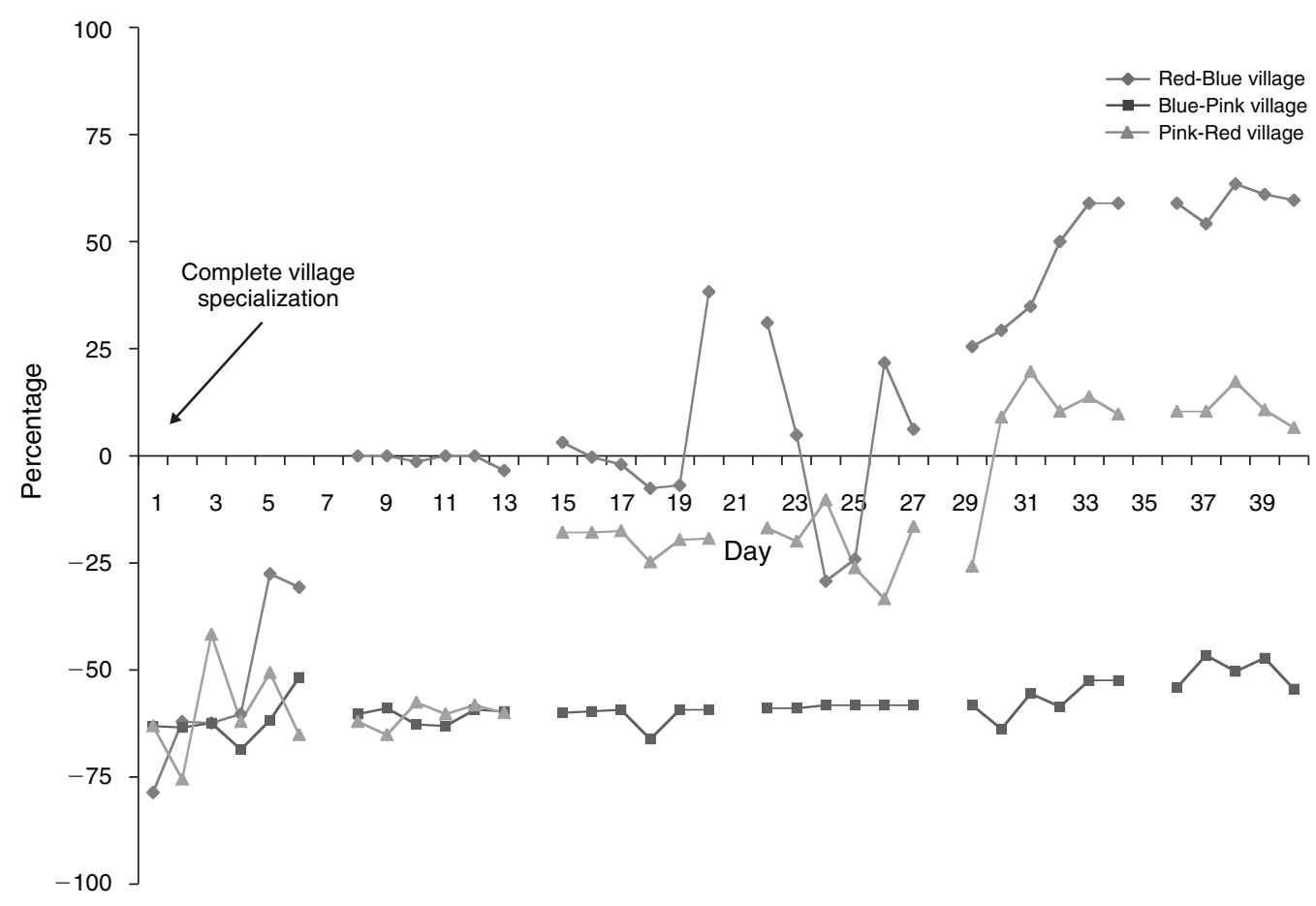

Figure 5. EFFicienCy by Village: NPRH3

The word "we" is noticeably absent in the merchant meeting area chat rooms. We quantify and further examine this observation for our eight sessions.

FINDING 4: The discussions in the meeting area are more impersonal than the discussions in the village chat rooms.

\section{EVIDENCE:}

To measure how personal or impersonal the exchanges are, we count the number of times the word "we" appears in the village chat rooms relative to the meeting area. The use of the plural pronoun "we" ties its user to another person or persons. While its usage does not always refer to a familiar, personal relationship, or necessarily imply a commonality between the writer and the subjects of the discourse, we have no reason to believe that a greater occurrence of the word would not be correlated with its increased usage in that sense. Table 2 reports the number of times that the word "we" is used in each village and meeting area. The difference between the number of times "we" is used in the village chat rooms and the meeting area is significantly greater than zero using an exact Wilcoxon signed rank test $\left(V_{8}=36, p\right.$-value $=0.0039$, one-sided test), i.e., "we" is used more often in the village than in the meeting area. Specifically, the villagers use "we" an average of 111 more times in a village chat room than in the corresponding meeting area chat rooms. In every session, "we" appears more often in the village chat room than in the meeting area.

FINDING 5: NPRH villages are less personal and community-minded than PRH villages. 
Table 2-Measures of the Personal and Impersonal

\begin{tabular}{|c|c|c|c|c|c|c|c|}
\hline Session/village & $\begin{array}{l}\text { "We" count } \\
\text { weeks } 1-5\end{array}$ & $\begin{array}{l}\text { "We" count } \\
\text { week } 5\end{array}$ & $\begin{array}{c}\text { Price quotes } \\
\text { weeks } 1-5\end{array}$ & Session/village & $\begin{array}{l}\text { "We" count } \\
\text { weeks } 1-5\end{array}$ & $\begin{array}{l}\text { "We" count } \\
\text { week } 5\end{array}$ & $\begin{array}{c}\text { Price quotes } \\
\text { weeks } 1-5\end{array}$ \\
\hline PRHI & & & & NPRHI & & & \\
\hline Red-Blue & 26 & 5 & 0 & Red-Blue & 47 & 1 & 1 \\
\hline Blue-Pink & 48 & 10 & 4 & Blue-Pink & 28 & 4 & 9 \\
\hline Pink-Red & 49 & 9 & 30 & Pink-Red & 63 & 6 & 1 \\
\hline Meeting area & 10 & 1 & 2 & Meeting area & 4 & 0 & 2 \\
\hline Total & 133 & 25 & 36 & Total & 142 & 11 & 13 \\
\hline $\mathrm{PRH} 2$ & & & & $\mathrm{NPRH} 2$ & & & \\
\hline Red-Blue & 39 & 5 & 0 & Red-Blue & 30 & 3 & 7 \\
\hline Blue-Pink & 80 & 11 & 24 & Blue-Pink & 36 & 3 & 1 \\
\hline Pink-Red & 70 & 6 & 3 & Pink-Red & 9 & 2 & 46 \\
\hline Meeting area & 2 & 1 & 34 & Meeting Area & 12 & 7 & 15 \\
\hline Total & 191 & 23 & 61 & Total & 87 & 15 & 69 \\
\hline$\overline{P R H 3}$ & & & & NPRH3 & & & \\
\hline Red-Blue & 28 & 9 & 0 & Red-Blue & 41 & 1 & 12 \\
\hline Blue-Pink & 47 & 12 & 2 & Blue-Pink & 38 & 9 & 0 \\
\hline Pink-Red & 45 & 9 & 0 & Pink-Red & 31 & 5 & 3 \\
\hline Meeting area & 9 & 1 & 9 & Meeting Area & 10 & 1 & 6 \\
\hline Total & 129 & 31 & 11 & Total & 120 & 16 & 21 \\
\hline PRH4 & & & & NPRH4 & & & \\
\hline Red-Blue & 67 & 9 & 5 & Red-Blue & 11 & 2 & 13 \\
\hline Blue-Pink & 35 & 5 & 6 & Blue-Pink & 16 & 3 & 52 \\
\hline Pink-Red & 55 & 6 & 2 & Pink-Red & 7 & 0 & 10 \\
\hline Meeting Area & 8 & 2 & 2 & Meeting Area & 1 & 0 & 42 \\
\hline Total & 165 & 22 & 15 & Total & 35 & 5 & 117 \\
\hline
\end{tabular}

\section{EVIDENCE:}

Over all 5 weeks, the 12 NPRH villages use "we" on average 30 times per village, whereas the $12 P R H$ villages use it 39 percent more, or 49 times. Treating each geographically separated village as an observation, this treatment effect is highly significant $\left(U_{12,12}=114, p\right.$-value $=0.0145$, two-sided test). This observation is even more pronounced when week 5 is considered alone; the average usage of "we" is 3.25 times per village in the $N P R H$ economies and 8 times per village in $P R H$ economies $\left(U_{12,12}=131.5, p\right.$-value $=0.0002$, two-sided test $)$.

KSW further notices that the tone of the transcripts is starkly different in the meeting area, reporting that merchants would fill the discussion in the meeting area by quoting prices as singleline text messages, e.g., "20/20" and "7 pinks for 7 blues." The villagers, however, do not use such phrases in the village chat room. KSW interprets the quoting of prices as evidence of impersonal exchange. Table 2 reports the number of price quotes in each village and the meeting areas. We define a price quote as a piece of text written by one subject containing two numbers referring to the explicit or implicit exchange of one quantity of goods for another. Contrary to the pilot session, and showing the importance of replication, we do not find more price quotes in the meeting area than in the corresponding village chat rooms $\left(V_{8}=36, p\right.$-value $=0.9961$, one-sided test), nor is there a difference in the total number of price quotes in an economy by treatment $\left(U_{4,4}=11, p\right.$-value $=0.4857$, two-sided test $)$, in the meeting area by treatment $\left(U_{4,4}=\right.$ $10, p$-value $=0.6857$, two-sided test $)$, or in the village chat rooms by treatment $\left(U_{12,12}=94.5\right.$, $p$-value $=0.1978$, two-sided test). 


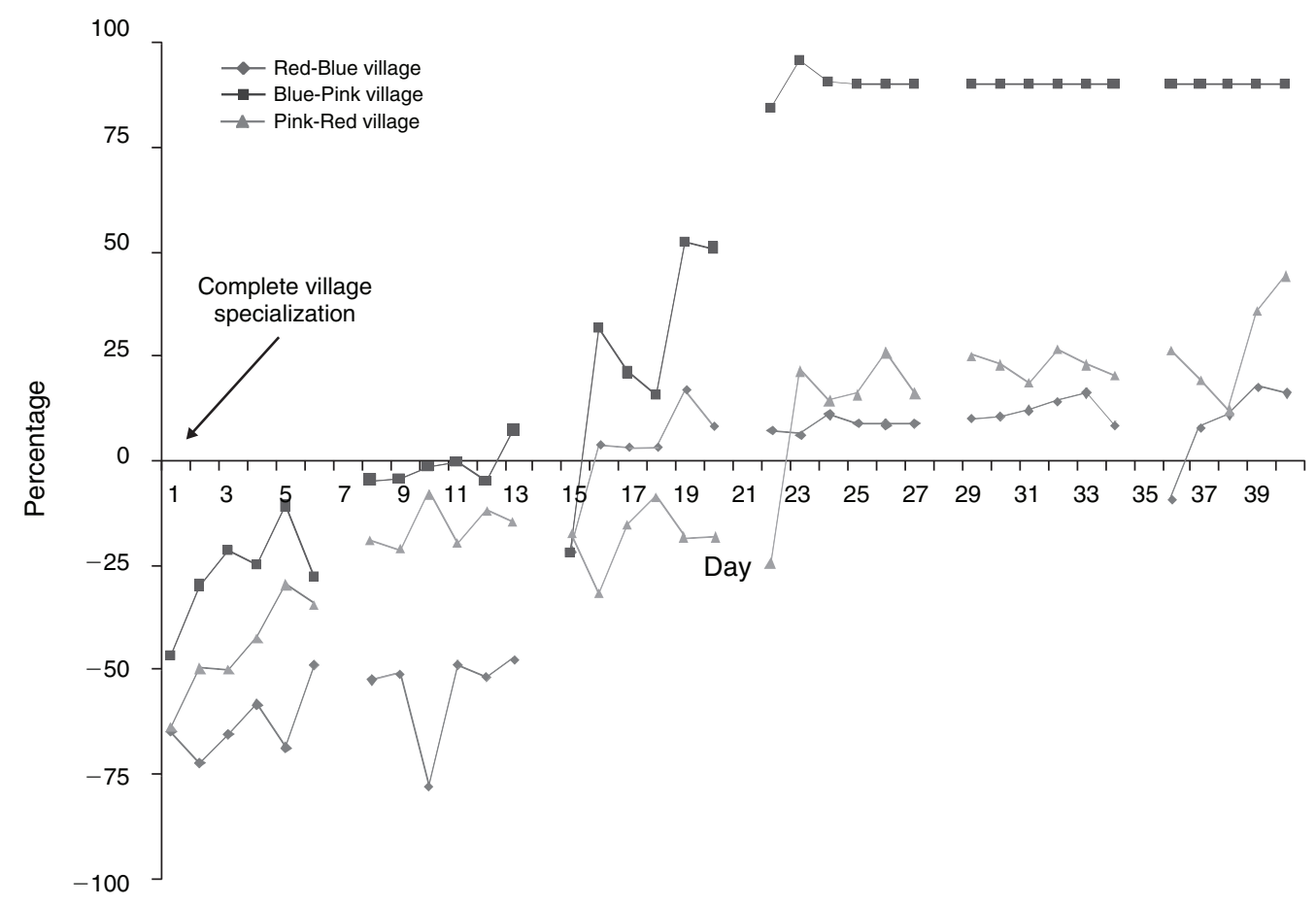

Figure 6. EfFiciency by Village: PRH3

\section{The Sociality of Personal and Impersonal Exchange}

The contrast between personal exchange within villages and impersonal exchange in the meeting area can be further demonstrated with a more detailed look at the behavior of the subjects as it is reflected in transcripts from the chat rooms. Quotations from these transcripts reveal the thoughts, beliefs, social attitudes, and experiential interpretations of the participants in ways that the quantitative measures of their behavior, above, cannot. The time-constrained subjects are busy interacting, implementing their choices; hence, their conversation is free-flowing and relatively unguarded. The narratives are a fascinating window into individual and group problem solving in real time.

First, the transcripts support our claim that the interactions in the merchant meeting area are noticeably more impersonal than those in the villages. The contrast of a brief snippet of a transcript from the chat room in a single village with that of a chat room from the common meeting area illustrates a flavor of this difference. Both of these conversations are from the PRH3 session. The first is from the blue-pink village. It starts on a day of rest and stretches a few periods into the future:

$* * * * *$ Day $21 * * * * *$

Producer5: how many more rounds of this?

Merchant8: i dunno

Producer6: no ide

Producer6: idea 
Producer5: i need to use the bathroom lol

Producer6: hehe

Merchant7: $i$ think it will till 8

Merchant8: 5 and $7 \mathrm{u}$ should be making the same amount of blue and pink

Merchant7: $i$ am making 100 percent blue and i only got 65

Merchant8: 6 u should have more total than me...ill do the trade

Merchant8: come back

Merchant8: and split it as evenly as possible

Producer5: imma make 95 percent blue since we alwasy got like 13 or so left over

Merchant8: listen

Merchant8: someone needs blue on the other side

Producer5: o ok

Producer5: i can make mad blues

Producer6: ahhhh the plot thickens...

Producer5: i give u 25 extra

Producer5: ok

Producer5: ?

Producer5: 100 percent blue

Day 24 begins and they complete their exchanges.

***** Day $24 * * * * *$

Merchant8: with $50 \mathrm{sec}$ to spare

Producer5: nice lol

Merchant8: and we're all zeroed out

Producer5: yup

Producer6: man the amount keeps changing they must still not have everything ironed out yet. i feel sorry for em

Producer5: thats good sign

Producer5: lol

Merchant8: the one who im trading pink with does

Merchant8: the one who im trading blue with always changes

Producer5: lol

Producer6: heh heh

Merchant8: but i think it will be consistent now.

The exchange occurring in this village is extremely personal. Notice the explicit differentiation of "we" and "the other side." Similarly, in PRHI merchant8 refers to his counterparts in the meeting area as "the "others." The geographical segregation of the villages is internalized into the subjects' conception of their own village as just that, their own. The villagers are quite proud of their own accomplishments (with 50 seconds to spare, no less), and they explicitly contrast that to the pity they feel for the groups that don't "have everything ironed out yet."

Furthermore, notice all the implicit cooperation in their language ${ }^{11}$ The villagers discuss their relative productive advantages and announce any upcoming changes in their behavior to the rest

\footnotetext{
${ }^{11}$ The explicit cooperation can be found in the transcripts, but it also shows itself in the fact that the members of this world are consciously smoothing consumption. From period 22 on, persons 5, 6, and 7 each consume exactly 60 cents worth of goods 1 and 2, while merchant 8 consumes exactly 40 cents worth. Merchant 8 imports between 45 and 50 units of the third good and spreads them almost completely evenly among the other members of his village. Though
} 
of the village, as if to ask for approval. The use of "we" in day 21 highlights this tendency: producer5 notifies the other villagers of a change in his production time allocation saying, "imma make 95 percent blue since we alwasy got liek 13 or so left over." He justifies his action not in terms of what it does for him, but in terms of the collective well-being of the village.

Now compare that to this transcript from the meeting area during the same time frame; the discussion here is all business:

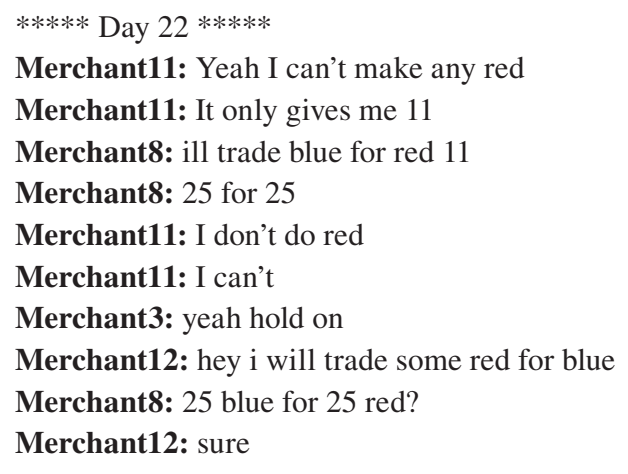

$* * * * *$ Day $23 * * * * *$

Merchant8: 12 same trade?

Merchant12: hey need some red

Merchant12: sure

****** Day $24 * * * * *$

Merchant12: hey 8 same ।

Merchant8: yep

Merchant4: trade blue for red anyone

****** Day $25 * * * * *$

Merchant11: You guys have no use for pink correct?

Merchant12: hey 8 same trade

Merchant11: Yeah I'm of no use here I believe

Merchant12: same thing 8

Merchant8: yep

Merchant8: just do it...dont even have to ask"

Subjects (particularly merchant 8 from the transcript above) quote prices, make trades, and return to their homes. Furthermore, though merchants in the meeting area are permitted to discuss any and all aspects of the experiment, at no point in any of the transcripts do they discuss home specialization or consumption. Even when they see goods being exchanged in the meeting area in numbers that are unheard of in their village, they never ask how such a large number of goods is produced or how they might acquire such quantities. And, on the days of rest, when all there is to do is chat, almost no interaction occurs in the meeting area.

The differences in social dynamics between the villages and the meeting area tell one part of the story, common across treatments. But what is it about the internal dynamics of the NPRH over these days. Respectively, they average $139.5,138.9,138.9$, and 96.8 cents over the previous three weeks. 
sessions that prevents them from achieving levels of specialization commensurate with those of the PRH sessions? To illustrate the different trajectories along which exchange evolved in these economies, we include narrative discussions of one session from each treatment. We chose PRH3 because it was the wealthiest of all the sessions and offers an archetypal example of the prerequisites for success. As a contrast, we also examine NPRH4 because it was the poorest of the sessions and offers a particularly poignant counterpoint to $P R H 3$. We also include NPRH3 to illustrate the mix of observations in PRH3 and NPRH4. Narrative discussions of all sessions are available as supplementary materials.

The stark contrast between these two sessions highlights the social characteristics necessary for successful specialization and exchange. Those economies and even villages within NPRH economies whose narratives read most like that of $P R H 3$ tend to be more successful, and those who read most like NPRH4 are much poorer. ${ }^{12}$ The lack of personal exchange in the villages of the NPRH economies retards their development by preventing the villagers from approaching their consumption and production issues cooperatively. ${ }^{13}$ Success hinges on the effective creation of multilateral networks of production and exchange, while a lack of sociality (which is correlated with a historic lack of property rights enforcement) hinders any attempt to develop such networks. Intervillage trade occurs at similar levels across the treatments, but if one does not have one's own village in order, the value of the third good diminishes significantly. ${ }^{14}$ Thus, while sessions in both treatments engage in roughly equal amounts of impersonal, distal exchange, the failure to adequately exploit the possibilities of personal, local exchange holds the NPRH economies back. ${ }^{15}$

What we learn about the process of discovery and wealth creation can be best described as follows: secure village property rights in personal property—homes and fields—encourage villagers to develop personal exchange and mutual trust. This trust yields implicit "contracts" that do not require enforcement, as repeat interaction provides self enforcement. Because these subjects can rely on one another without explicit enforcement, when opportunities for long-distance trade in a third good are introduced, this property rights history sets the stage for impersonal trade and increased specialization across villages. In other words, the implicit contracts serve the purpose

\footnotetext{
${ }^{12}$ The blue-pink village in NPRH1 is an example of the former. The interaction begins with a business-like attitude. The villagers organize production and consumption from the outset and begin to exchange on the first day, but most of the interaction focuses on terms of trade and differences in ability. They first engage in intervillage trade on day 10 , and they are 99 percent specialized three days later. As they realize the value that they can provide for one another, the interaction slowly changes from impersonal to personal. Each time merchant 8 returns with red, he receives congratulations from the producers, and they slowly work out exchanges so that each person contributes and each receives a portion of the imported reds, though merchant 8 consumes 1-4 more reds than the others. Much like the situation in the red-blue village, the merchant 7 who specializes in producing blue, which has no value on the intervillage market, quickly becomes excluded. And again, after a time, the other villagers attempt to help their fellow villager out with suggestions regarding his behavior. They do not, however, offer any direct charity, presumably because merchant 7 has never been able to provide anything for them. Their ambivalence can be seen clearly in this quotation from day 32 : "Sometimes I feel bad for 7. Sometimes."

${ }^{13}$ The villages in PRHI illustrate that specialization at home is necessary to take advantage of long-distance trade, but it is not sufficient. A personal social community among the four members of the village also appears necessary. If the producers and merchants do not develop personal social bonds, the merchants cannot take advantage of their ability to transport the third good and the producers cannot take advantage of their ability to produce goods to trade for the third good.

${ }^{14}$ As producer6 in PRH1 says on day 36, the merchants and their buckets are "like a ready bake oven ... throw in some blue and pink and wa la you got red."

${ }^{15}$ An oft-asked question is whether the subjects just need more time to learn how to implement more efficient production, exchange, and consumption decisions. But isn't it curious that some economies and villagers do not need more time? Our time constraint appears to be about right in yielding a diversity of outcomes that helps us to understand what factors account for better or worse performance. Learning is not an explanation of economic phenomena; rather, it is something to be explained, and a history of property rights appears to be critical to the process of exchange and specialization.
} 
that an explicit contract would in that they allow subjects to move their attention from solving the problem of local exchange to solving that of distal exchange.

An outsider observing these economies with the knowledge of the experimenter or that of a trained economist could assert that these subjects are presumably aware of many capabilities, including exchange and specialization, and that what the subjects are discovering is something specific to this particular interface. But such an observer lacks the perspective of the subject, or better put, such an observer possesses additional perspective that is not available to the subject, and projects this additional knowledge into his personal interpretation of the experiment. Our response is simply that wherever or however people began exchanging in history, they did so by learning to interface within the specific context in which they lived and in that process discovering the specialization benefits of exchange. On this dimension, our laboratory experiment is no different in principle from the naturally occurring economy, historical or contemporary. All of our economies are endowed with an identical environment, and yet across our replications we are observing a fascinating diversity with which each economy organizes itself. At the same time, we observe similarities interwoven within these differences, and that is how we can begin to understand the evolving process of exchange and specialization.

Narrative for PRH3.- The distinctive characteristic of this economy is its high degree of specialization. By day 8 , all six merchants are fully specialized. The producers, however, vary in their degree of specialization over the last 12 days: averaging 70 percent in the pink-red village, 90 percent in the red-blue village, and 100 percent in the blue-pink village.

From the beginning of the session, the villagers form "teams" in the red-blue village; producer 2 and merchant 3 pair off, as do producerl and merchant4. By day 5, however, the producers form one team, the merchants another, and these pairs remain separated for the entire session.

The red-blue merchants are thinking early on (even before specializing) about long-distance trade, as shown by such comments as, "i don't see anyone making pink" in period 2 and "ok how does the traveling hwo?" in day 7. In day 10, merchant 3 and merchant 8 agree in principle to trade " 5 pink for 5 red," and from day 12 on, they trade at a one-to-one ratio every day reaching a steady state volume of 25 pink for 25 red in day 19 . When merchant 3 first returns with pink in day 12, producer 2 exclaims, "HEY WHOOA where are the pinks coming from?!?!." Except for a couple of rare occasions, merchant 3 shares his pink only with his partner merchant4. With this pink, the merchant pair earns $\$ 1.30$ on average as a team over days $29-40$, as compared to the $\$ 1.52$ for the producer team. Producer 2 makes frequent requests, pleas really, to merchant 3 and merchant4 that "we could all make bank if we worked together" and "seriously tho ... if me and \#1 could get some pinks, we could afford to give away some of our reds and blues to give you guys a better profit," but merchant4 replies that the other partnership is not interested: "it sounds complicated, I'm afraid it'll get messed up," and merchant3 says "uhm. Would that just be more trouble 4?" In day 38, producer2 makes the following observation:

Producer2: $i$ think the people running this experiment are wondering why everyone is always so anxious to get a partner first thing and then are sooo adamant about not changing their set pattern...i think it's like people who still mail their bills instead of paying online...

Producer1: haha, could be

Producer2: it's the market!! take risks!! especially cause it's a fake market!! ${ }^{16}$

\footnotetext{
${ }^{16}$ Notice that the market is perceived as "fake," but unperceived is the fact that it enables specialization and individual betterment in the form of greater cash earnings, and this is not "fake." In these experimental economies, we control
} 
The blue-pink village stands out from all of the rest. First, the exchanges among the blue-pink villagers, nearly from the beginning, are multilateral, and by day 5 the entire village is completely specialized. From the first day on, the villagers are champing at the bit to get the third good, red, saying: "7 and 8 prolly have to travel to get reds from the other people" in day 1, "we need those reds" in day 3, "man i wish that other room would get some people" in day 4, and "you see if we can get those reds yet?" in day 6. When merchant 8 first brings red back, he asks, "what do i do with the red," to which producer6 replies, "pass em out," i.e., pass them out evenly. Starting with day 25 , merchant 8 gives himself 14 reds and the other three villagers each receive 12. ${ }^{17}$ The personal exchange of this village is quite evident in day 25 's conversation:

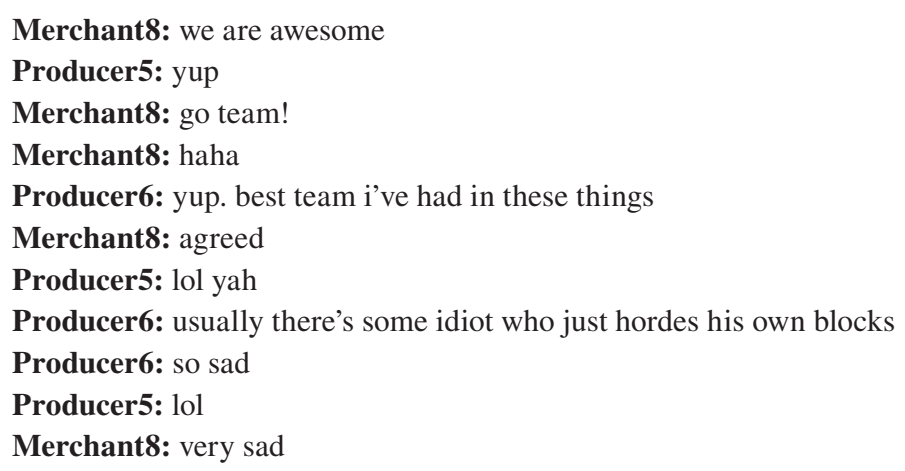

The conversation in the blue-pink village also reveals out-group and in-group attitudes among the village members:

Merchant8: btw people are now JUST learned [day 39] what others need and how to trade

Merchant8: i kinda wanted to laugh at them

Producer6: heh heh

Merchant8: listen someone needs blue on the other side

Producer5: o ok

Producer5: I can make mad blues

The most distinguishing feature of this village is that it is the wealthiest of all 24, notably because, in addition to being fully specialized, merchant 8 trades 25 pink and 25 blue for 50 red, 25 from each of the other two villages. Merchant 8 summarizes it this way in day 33:

Merchant8: u know whats funny

Producer6: what's funny?

Merchant8: i wonder if the other ppl that im trading with realize that im trading with 2 people and getting twice as much ...

Merchant8: i mean i trade 25 with both of them

Merchant8: but i get 50 total

Merchant8: and they only get 25

only their potential to perform, and it is amazing to observe different spontaneous orders across different economies and different villages within the same economy.

${ }^{17}$ As stated above, the earnings of the other three villagers are \$1.39/day/person while merchant8's earnings are \$0.97. Producer6 offers to equalize merchant8's earnings in period 20 but the merchant declines " $u$ don't need to do that." 
Merchant8: and nobody else is really trading

Merchant8's observation is notable; he is expressing something deep in his surprise that others are not stumbling onto the welfare-enhancing power of long-distance trade. This is intriguing because it precisely highlights one objective of this project- to observe how subjects discover, implement, and develop long-distance exchange via impersonal networks. We are observing that subjects apparently learn and imitate how to implement opportunities more readily in personal exchange than in impersonal exchange. Why is that? Because the merchants are more cognizant of the circumstances of the local villagers than they are of those with whom they engage in distal exchange. Learning, it seems, occurs by analogy. With no guarantee of shared experience between the members of the separate villages and without the wholly tacit understanding that they share similar experiences in the villages, merchants do not even bother to look to the merchants from other villages to find ways of improving their production, consumption, etc. They have no evidence that others face similar circumstances, and as a result, they assume that they have nothing to learn from these other individuals.

In the merchant trading area, there is no discussion of profits or how to maximize the welfare of the merchants of different villages. It's business: "all right 20 for 20 pink," "same thing 8," "yep," and "just do it ... don't even have to ask." Hence, if a merchant from the red-blue village is not aware why merchant 8 from the blue-pink village is trading to take home 50 reds, then the welfare benefits are not obvious for trading to take back 50 pinks to the red-blue village.

Why didn't they think, "if 25 pinks are good, 50 must be better"? Because one has to know the extent to which the third good increases earnings. As producer6 says, "maybe this means the other room has figured out that multipliers are good." But the goodness of 25 units of the third good may not be the same for both you and me, and that is precisely the point. An individual knows more about the circumstances of those with whom he engages in personal exchange than those with whom he impersonally exchanges.

The pink-red village can be characterized as a combination of the other two villages. Just like the red-blue village, the pink-red villagers try to form two producer-merchant pairs, but on day 16 , producer 9 initiates the following discussion:

Producer9: I actually think that if 10 and I work together it would be better

Merchant11: ?

Producer9: cause I make a lot of pink and he makes a lot of red and we can balance it out

Merchant12: ok i think we all need to work together

Merchant12: thats why it is four of us in this room

Merchant11: Yeah if the smaller producers work together they make a smaller profit

Thereafter, exchange among the villages becomes multilateral, though the producers still earn a little more than the merchants for the last half of the session $(\$ 0.83 /$ day/producer versus $\$ 0.72$ / day/merchant). These villagers take much longer, until day 21 , to discover the benefits of longdistance trade:

Merchant11: So $9 / 10$ got the ability to produce many more than $11 / 12$

Merchant11: But 11/12 got the ability to travel, which I still don't see a point to

Producer10: yeah, what IS the point of travelling

Merchant11: No clue

Producer10: okay so i switched to 90 percent red, 10 percent pink

Producer9: Hey 11 or 12 see if you can travel and pick up blues anywhere

Merchant11: Oh God 


\section{Producer10: i was JUST GONNA SAY THAT}

Merchant12: there is a point in trying to trade with the others but we havebe to fine a patter with us first to go ahead and start something new

Producer10: smart thinking!

Merchant11: I think that's what it was

Merchant11: That's a little too much

Producer9: cause we need the blues for upping profit

Producer10: right

The red-blue and blue-pink villages have been trading for several days by this point, yet where do the pink-red villagers discover the benefits of long-distance trade? From within their own village. Immediately after this discovery in day 22 , merchant 12 begins a trading relationship with merchant8, exchanging 25 red for 25 blue for the remainder of the session. However, the welfare-enhancing power of this exchange is limited at home because the producers in the pinkred village are the least specialized (70 percent) in this economy.

Just as in the blue-pink village, this merchant divides the third good evenly among the four members of his village, to the point of rotating the twenty-fifth unit across the four villagers from day to day. On day 39, merchant11 begins trading 8 pink for 8 blue with merchant 4 from the red-blue village.

Narrative for NPRH4.- This is the only economy in which no village is over 90 percent specialized at any point during the session: over days 29-40, the red-blue village is 73 percent specialized, the blue-pink 44 percent, and pink-red 61 percent. As a result, this session is the poorest of the eight economies.

All the subjects in the red-blue village begin in autarky. Producerl and merchant4 discuss exchanging on the first day and are surprised to learn that they cannot take goods from one another.

Producer1: hey four need any blues?

Merchant4: yeh

Producer1: you cant take em from me can you?

Merchant4 suggests that they specialize, and they spend the next two days deciding who will specialize in which good. The other two villagers do not even begin to interact with producerl and merchant 4 until the first day of rest, and they do so only because a discussion starts up about the third good. No more discussion of pink ensues, but on day 10, merchant 3 imports it for the first time. The others continue to specialize and exchange, but only producerl and merchant4 ever manage to specialize completely.

On the second day of rest, the villagers resume their discussion about how to acquire pink.

Producer1: where were you at last turn \#4?

Merchant4: trying to pick up some pink

Producer1: lol

Merchant4: im back in it now

Producer1: good call

Merchant4: haha

Merchant4: theyre not sharing the pink

Producer1: its hard to get em to sometimes

Merchant3: i can get some pink 
The merchants agree to continue looking for it, but they are not successful until day 16. Merchant3 returns with pink, and producerl trades him 40 red for 7 pink.

This stands in contrast to the rates of exchange in other sessions and provides evidence for a lack of cooperation and trust in the village. Merchant 3 neglects to share with anyone when he first obtains pink on day 10 . He is protective of his pink and trades only when a very generous deal is struck. Neither merchant 3 nor merchant 4 has secured a consistent trading partner in the meeting area, so they keep what little pink they can acquire for themselves.

The shift of the merchants' attention to the acquisition of the third good drives producerl and producer 2 into a tighter relationship, as merchant 4 begins to ignore his previous trade relationship with producerl. Once the third day of rest arrives, they discuss this and agree to resolidify their relationship, stating explicitly what they will exchange each turn, and without any suggestion on the part of merchant4, producerl offers to increase his relative contribution, likely as a response to the threat of competition.

These trade relations congeal, yet the interactions remain largely impersonal. The villagers discuss their exchanges and nothing more. Merchant 3 continues to import pink, but eventually merchant 4 loses his connection and has to trade with merchant 3 to receive it. They work out a larger series of trades during the fourth day of rest:

Merchant4: 3 if you get me pink ill hlp you out

Merchant3: aight

Merchant3: yeah i got u

Merchant4: what do you need

Merchant3: $i$ think ima need blue and red

Merchant4: all work in some sort of system

Merchant3: yeah

Merchant4: ok

Merchant4: well i trade some with 1 and i usually have too many blues... ill see what i can do

Producer1: you want more red \#4, I'll always take more blues?

Merchant4: yeh

Merchant4: so you give 35 ill givr 20

But otherwise they simply continue the previous pattern of exchange. Notice the way in which the exchanges are discussed. Merchant 3 brings in pink, and the others try to trade with him for it. And the cooperation is still made explicit, "if you get me pink ill hlp you out." This continues to the end of the experiment without much additional growth. Over the final two weeks the villagers earn $\$ 8.49, \$ 4.03, \$ 5.20$, and $\$ 5.57$, respectively.

The blue-pink villagers do not begin to talk until the second day. They are also extremely slow to exchange and specialize. The villagers begin discussing the third good, red, on day 4, but their discussion centers around their lack of knowledge regarding its whereabouts.

\footnotetext{
Merchant8: need pink anyone/

Merchant8: i need pink plz!

Producer5: need pink 2

Merchant8: would love red actually!

Merchant8: ill trade somethin 4 red
}

They beg for it, plead for it, and ask to trade for it, but not until the first day of rest do they all realize that they cannot acquire it in their village. 
Merchant8: ok break time

Merchant8: so did anyone have red durin any of that?

Producer5: no

Producer6: it looks like no one did if you look at the dominos

Producer6: this is weird

Merchant7: it says zero for all

Then the next day, merchant 7 brings red back from the meeting area. He takes the first batch all for himself, and on the next day he begins to trade red for other goods with the members of his village.

The exchanges within this village display a distinct lack of trust among some of the members. Producer6 asks his co-villagers to give him some red or blue in exchange for pink, but he explains that he won't trade unless they move the goods first:

\author{
Merchant7: i need pink \\ Producer6: person 7, i have pink \\ Merchant7: i'll trade 1 reds for 3 pinks \\ Producer6: but you must send the reds over 1st
}

Also, much of the chat room discussion is very business-like; the villagers quote prices to one another. On day 13, producer6 tries to trade for red with merchant7, but the merchant will not give him more than one of the 20 he has acquired.

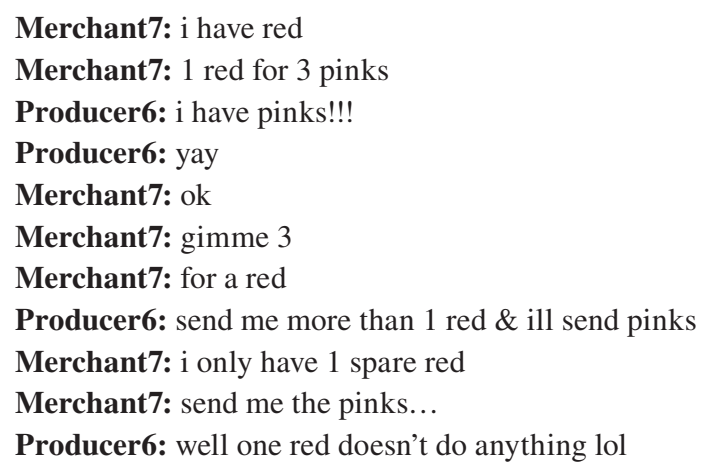

Because a single red provides no additional benefit, there is no exchange.

The price quotes continue as specialization stagnates. Even in the rest periods, price discussions continue:

Merchant7: \#6, I'll trade u 3 reds ofr 6 pinks every time ok? ... and \#5, i'll trade 3 reds for 18 blues

Producer5: that's not fair

Producer6: so, say, say could make blues \& i could make extra pinks

Producer6: 5 do you need more blues or pinks?

Merchant8: i need more blues

Producer5: red

Producer5: i'll produce more blue then

Producer6: i need more pinks

Merchant8: yes, u produce more blue \#5

Merchant8: and \#6 produce a lil more pink 
Producer5: to trade red from 7

This blatant unequal treatment within the village highlights the tendency of their interactions to lean toward impersonal exchange. These trends continue, and merchant 8 also begins to import red. The producers continue to deal with merchant 7 in order to acquire red until day 30 when merchant 8 begins to offer some of his red to the others.

The lack of trust is still evident in day 34 :

Merchant7: person 8, 1 blue for 1 red?...

Merchant8: u first hurry

Cooperation in the pink-red village is also fairly slow to develop, and this impedes specialization (see Figure 7 for a plot of the efficiency by village). Notably, only the merchants in this village ever specialize completely and the producers decrease the extent of their specialization over time, eventually settling at 61 percent. The interactions between these villagers are largely impersonal, and at times nonexistent. They spend a lot of time quoting prices at one another, and they do little other chatting. In most sessions we observe no interaction in the common meeting area during the days of rest. This session is no outlier in that regard. But we also see the same impersonal behavior within this village that is typically limited to the meeting area. In all but the first day of rest, there is absolutely no chatting whatsoever among the pink-red villagers.

As early as the tenth day, merchant 12 begins importing a substantial amount of blue, but he almost always retains it all for himself. This continues until the twenty-second day when he trades some to merchant11 for the first time. For a few days, there is no one in the meeting area to provide the blue, and some discussion results from that. However, on day 31, trade takes off and discussion tapers off. No talking at all occurs during the last four days, and there are a total of eight wordless days. The behavior in the merchant area is typical-the interaction is largely price quoting and discussion surrounding the establishment of trading relationships. These villagers earn a total of $\$ 4.29, \$ 5.52, \$ 6.86$, and $\$ 6.10$ over the final two weeks.

Narrative for NPRH3.-The three villages in this economy are rather different: the red-blue village is, on average, 88 percent specialized over days 29-34, but lacks social cohesion, with one merchant completely withdrawing from the community; the blue-pink village is 100 percent specialized over the same time frame but is engaging in only minor intervillage trade; and the pink-red village wallows near autarky for the whole session and also noticeably lacks personal interactions.

The most severe breakdown of the interpersonal relationships involves merchant4. Apparently unhappy with his station in the experiment, he exclaims on day 16, "listen, im getting d[*]cked over in this particular exp, so dont worry about me." During the day 21 rest time, merchant 3 initiates the following conversation:

Merchant3: 4, we gonaa work it out to cut you back in?

Producer2: yea poor 4

Producer1: how are we gonna do that

But, merchant4 never says anything and appears to have completely withdrawn to be selfsufficient in the merchant area. The other three villagers cooperate with each other with merchant 3 securing pink from merchant 7 and dividing the product nearly evenly among the three of them. 


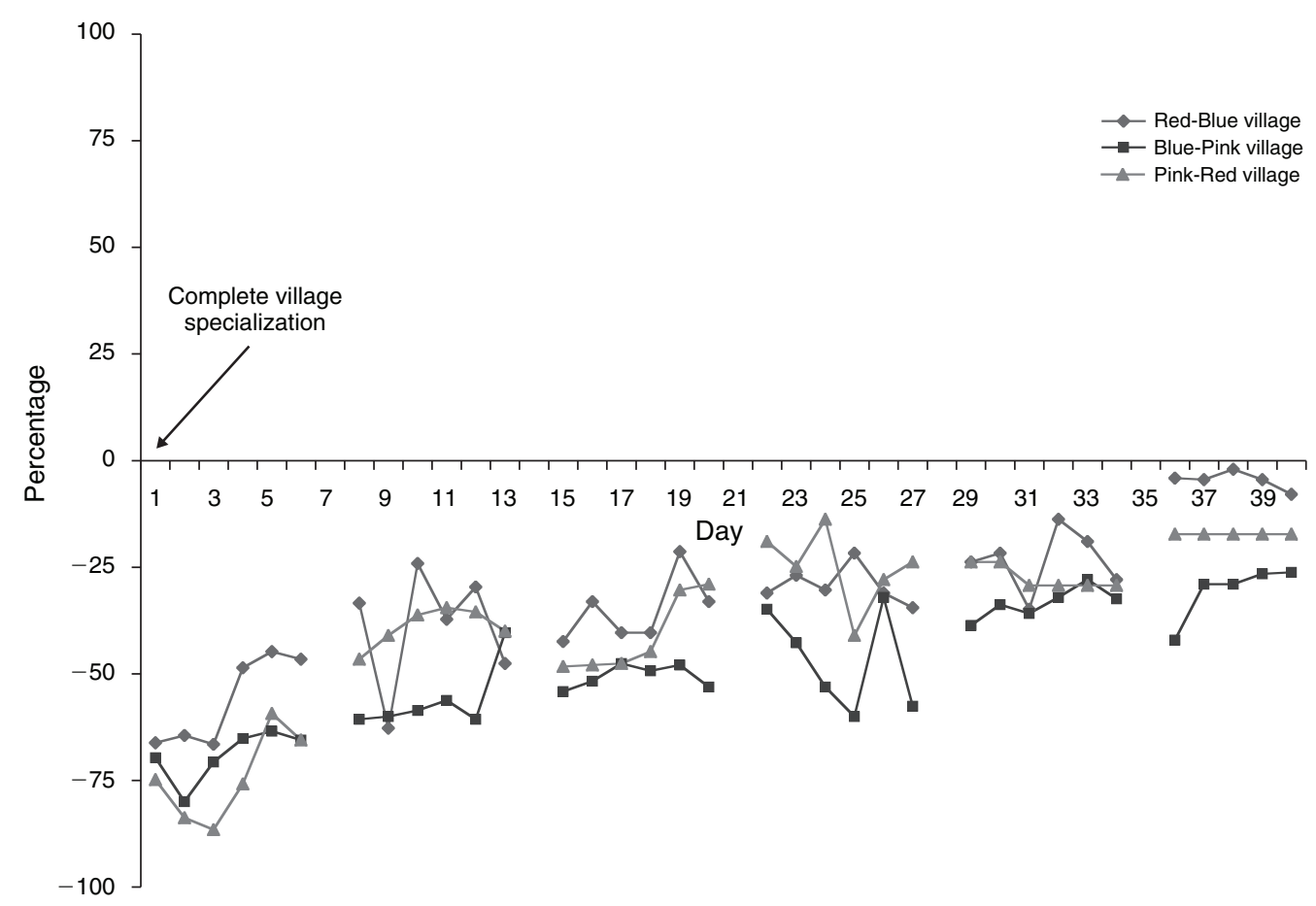

Figure 7. EFFiciency by Village: NPRH4

In contrast, the blue-pink village is highly social and cooperative with merchant 8 setting the tone right away in day 1: "we are going to need to cooperate in order to do best." During the rest on day 7 , the entire village solidifies its group mentality and agrees to 100 percent specialization in production and cooperation:

Merchant8: are we doing the smartest trading

Merchant8: does anyone see anything smarter to do

Merchant8: or is this the best way

Merchant8: is eveyone max producing one color

Producer5: no $i$ think this is good

Producer6: i think so too

Producer5: no im doing 70/30 blue to pink

Merchant7: its straight

Merchant7: I'm doing 100 percent blue

Producer5: should we max produce

Merchant8: im doing 100 percent pink

Merchant8: lets try max producing

Merchant8: and see what we can do

Producer5: me and seven can do all blue and 6 and 8 do all pink

Like the red-blue village, the pink-red village lacks social cohesion, with one member, merchant 12 , eventually withdrawing from the community. On day 2, merchant 12 plants the idea of specialization and cooperation, but it does not go anywhere: 
Merchant12: We can set this up so that two people make all pink, and two people make all red, and see if we can't manipulate things.

Merchant11: ok.. im with it

Merchant11: what should i do

Producer9: give me all of your tokens

Merchant12: Hah. That's where the game breaks down.

This is the first and last time anyone ever discusses specialization and they all produce near the autarky levels. They do exchange small numbers of extra units here and there, but what is unique about this is that they do so with the distinctly impersonal touch of quoting prices back and forth to each in the village: "ill give 2 reds for 1 pink, 2," "10 pink for 3 red," "\#12, 5 pink for 2 red." Eventually this leads merchant 12 on days 12 and 14 to proclaim:

There's got to be some way to do this on a self-sustaining basis...either that, or we're not trading effectively. ... There's got to be a better way, and it's probably by self-sustainment. Enough of this touchy-feely trading stuff.

\title{
V. Conclusions
}

We set out with this paper to create an experimental environment in which our subjects could develop a system of market-like exchange. We compare two treatments wherein our subjects experience different historical property rights regimes. In both treatments we observe specialization and the creation of networks involving both personal and impersonal exchange. The networks evolve and progress to highly varying degrees that appear dependent to a large extent on the context in which their members understand them. Of particular interest is that the $P R H$ treatment produces both wealthier and more equitable economies than the NPRH treatment, when we introduce the possibility of long-distance trade.

We also observe impersonal exchange in its nascence emerge out of a personal exchange economy in a way that would be difficult, if not impossible, to observe in historical data. The following quotations from NPRH2 summarize the difference between the personal village and the impersonal meeting area on the same day 33:

\author{
****** Blue-Pink Village $* * * * *$ \\ Producer5: is the other room cooler than this one? \\ Producer6: i wanna travel... \\ Merchant8: not really \\ Merchant8: you just make deals \\ Merchant8: it has a chat board \\ Merchant8: and buckets \\ Merchant8: thats it \\ Merchant7: yea \\ Merchant7: pretty much
}

***** Meeting Area *****

Merchant12: Why does it feel like we're selling illegal drugs behind Denny's when we're doing this?

Merchant4: cause we are 
It is clear from the difference in tone that the villagers distinguish between the realms of personal and impersonal exchange. Personal exchange in the village is "cool," but for impersonal exchange in the meeting area, "you just make deals ... thats it."

This distinction between personal and impersonal exchange is at the heart of North's argument in Understanding the Process of Economic Change. Social histories composed of belief systems and local knowledge and institutional histories composed of legal and structural rules provide the grounds out of which future developments in exchange must grow. Our experiment demonstrates North's principle that "path dependence is a fact of history and one of the most enduring and significant lessons to be derived from studying the past. ... the learning process by which we arrive at today's institutions constrains future choices" $(2005,77)$. We find that diverse prior experiences elicit varied behavior in shared future experiences. Those in the NPRH treatment fail to specialize and exchange to the same extent as those in the $P R H$ treatment. They trade an equally high volume of goods between the villages, but the total volume of goods produced in the $N P R H$ economies is significantly lower. As a result, total earnings are over 30 percent lower as well.

Moreover, even though the environment in each economy is precisely the same, each replication displays unique traits and develops according to its internal dynamic. As North (2005) also notes:

No economic model can capture the intricacies of economic growth in a particular society. The process of economic growth is going to vary with every society, reflecting the diverse cultural heritages and the equally diverse geographic, physical, and economic settings. ... You must have an intimate understanding of the individual characteristics of that society before you are ready to try to change it (165).

We would add that even if you believe you have an intimate understanding of a society, it remains to be seen that trying to change it will be successful.

What we have captured is a sort of idealized economic history in the laboratory. But where do we go from here? More than merely answering questions, this experiment has developed a platform and method of study that opens up a host of new issues by identifying just how little we really know about the evolutionary process of personal and impersonal exchange. For example, what would happen if subjects were allowed to rent their productive capacities (i.e., the control of their fields, buckets, etc.) to others in the experiment? Would the ability to transfer ownership result in increased skill specialization and thus also increased consumption? Furthermore, the experiment may have something to say about development from the perspective of property rights. There is much diversity in trade and growth across economies we see in the world, and our experiment mimics this observed diversity. What social dynamics foster that confidence in property rights systems that appear to be so instrumental to the full exploitation of the gains from long-distance trade?

There are all sorts of environmental variations that would go further to illuminate the role of context in shaping the character of specialization and exchange. What if the merchants' homes and fields are all moved to the meeting area, so they must approach the producers as outsiders? How would this affect the relationships we observed among the producers and merchants? Would the merchants start quoting prices to producers? Would the merchants take higher margins for themselves? Would collusion occur, or would competition between merchants mitigate such behavior? Would the addition of endogenous commodity money help increase the extent of specialization and exchange? The possibilities are truly open-ended, and for each different arrangement we try, it seems likely that we may see strikingly different results, and hence gain additional insights. 


\section{REFERENCES}

Crockett, Sean, Vernon L. Smith, and Bart J. Wilson. 2007. "Exchange and Specialization as a Discovery Process." George Mason University Working Paper.

Dixit, Avinash K. 2004. Lawlessness and Economics: Alternative Modes of Governance. Princeton: Princeton University Press.

Ellickson, Robert C. 1991. Order without Law: How Neighbors Settle Disputes. Cambridge, MA: Harvard University Press.

Greif, Avner. 1993. "Contract Enforceability and Economic Institutions in Early Trade: The Maghribi Traders' Coalition.” American Economic Review, 83(3): 525-48.

Greif, Avner. 2006. "The Birth of Impersonal Exchange: The Community Responsibility System and Impartial Justice." Journal of Economic Perspectives, 20(2): 221-36.

Kimbrough, Erik, Vernon L. Smith, and Bart J. Wilson. 2008. "Building a Market: From Personal to Impersonal Exchange." In Moral Markets: The Critical Role of Values in the Economy, ed. Paul J. Zak, 280-99. Princeton: Princeton University Press.

Kranton, Rachel E. 1996. "Reciprocal Exchange: A Self-Sustaining System.” American Economic Review, 86(4): 830-51.

Kranton, Rachel E., and Deborah F. Minehart. 2001. "A Theory of Buyer-Seller Networks." American Economic Review, 91(3): 485-508.

Kumar, Krishna B. and John G. Matsusaka. 2006. "Village Versus Market Social Capital: An Approach to Development." University of Southern California CLEO Working Paper C05-5.

North, Douglass C. 1990. Institutions, Institutional Change, and Economic Performance. Cambridge: Cambridge University Press.

North, Douglass C. 1991. "Institutions.”Journal of Economic Perspectives, 5(1): 97-112.

North, Douglass C. 2005. Understanding the Process of Economic Change. Princeton: Princeton University Press.

Smith, Adam. 2003. The Wealth of Nations. New York: Bantam Dell. (Orig. pub. 1776.) 